ISSN 2073-4360

www.mdpi.com/journal/polymers

Review

\title{
Biodegradable Cell-Seeded Nanofiber Scaffolds for Neural Repair
}

\section{Dong Han * and Karen C. Cheung}

Department of Electrical and Computer Engineering, The University of British Columbia, Vancouver, BC V6T 1Z4, Canada; E-Mail: kcheung@ece.ubc.ca

* Author to whom correspondence should be addressed; E-Mail: dhan@ece.ubc.ca; Tel.: +1-604-827-4114; Fax: +1-604-822-5949.

Received: 24 August 2011; in revised form: 14 September 2011 / Accepted: 6 October 2011 / Published: 10 October 2011

\begin{abstract}
Central and peripheral neural injuries are traumatic and can lead to loss of motor and sensory function, chronic pain, and permanent disability. Strategies that bridge the site of injury and allow axonal regeneration promise to have a large impact on restoring quality of life for these patients. Engineered materials can be used to guide axonal growth. Specifically, nanofiber structures can mimic the natural extracellular matrix, and aligned nanofibers have been shown to direct neurite outgrowth and support axon regeneration. In addition, cell-seeded scaffolds can assist in the remyelination of the regenerating axons. The electrospinning process allows control over fiber diameter, alignment, porosity, and morphology. Biodegradable polymers have been electrospun and their use in tissue engineering has been demonstrated. This paper discusses aspects of electrospun biodegradable nanofibers for neural regeneration, how fiber alignment affects cell alignment, and how cell-seeded scaffolds can increase the effectiveness of such implants.
\end{abstract}

Keywords: neural regeneration; electrospinning; nanotechnology; polymer; nanofibers; bioconduits; biomaterials; axonal guidance

\section{Introduction}

The nervous system comprises the peripheral nervous system (PNS) and the central nervous system (CNS). The PNS obtains information from the environment and transports signals from and to the 
CNS, which consists of the brain and the spinal cord [1]. Neural injuries are traumatic. Spinal cord injury (SCI) often leads to loss of motor and sensory function, chronic pain, and permanent disability. The estimated lifetime healthcare costs for an individual injured at age 25 with C1-4 level tetraplegia are more than $\$ 4$ million [2]. Although there are some pharmacologic, biologic and cell transplantation treatments for acute SCI, some of which are currently in clinical trials, there are not yet any established therapies which repair the damage and provide neurologic recovery [3-8]. After the initial mechanical damage on the spinal cord in SCI, a series of secondary events including the presence of growth inhibitors, adult neuron death, absence of trophic factors, immune system reactions and formation of scars and cystic cavities further complicate the axonal regeneration and functional recovery from SCI [9-16]. However, axonal regeneration can occur and reconnect with the distal stump if guidance is present, resulting in restoration of function for patients [17-20]. Strategies that bridge the site of SCI and allow axonal regeneration will likely have a large impact on restoring quality of life for these patients. Compared to SCI, peripheral nerve injury treatment is more promising due to the greater capacity of peripheral nerve fibers for regeneration. Conventional treatments for peripheral nerve injury include microsuture of the nerve stumps when the nerve gap is small and autografts when the nerve gap is beyond suturing. Only small nerve gaps can be treated with both treatments [1]. Furthermore, donor tissues are required for autografts, which will likely lead to function loss at the donor sites and formation of neuroma [1]. Autografts may also be compromised by the limited source of material for serious injuries and mismatching of donor and recipient tissues [21]. Therefore, extensive effort in the past few decades has been expended to develop alternative treatment methods for nerve injuries. Many groups have proposed using artificial guidance channels, or conduits, which serve as the support scaffolds that mimic extracellular matrix (ECM) to bridge the defective nerve gaps and guide cellular contact for both central and peripheral nerve injuries. However, using empty guidance channels alone hardly produces satisfactory results. Thus, when designing guidance channels made from either hydrogel $[18,22,23]$ or polymer fibers, the following factors require consideration: they should be biodegradable, biocompatible, and permissive for cell growth; include neurostimulatory extracellular matrix (ECM) macromolecules (such as laminin-1 or laminin-1 fragments); include supportive cells, such as Schwann cells and stem cells; and include neurotrophic factors, such as neural growth factor (NGF-See Table 1 for abbreviations of materials in this paper) and brain-derived neurotrophic factor (BDNF) [24-34].

The electrospinning technique has been widely used to fabricate porous and highly spatially interconnected micro- and nano-scale polymer fibers, both natural and synthetic, with a large high surface to volume ratio, which can then function as scaffolds for neural repair $[35,36]$. For instance, as a method to fabricate guidance scaffolds or conduits, the electrospinning technique enables the production of biomimetic nano- and microstructures which can then be mechanically and/or chemically optimized to treat nerve injury. Due to the nature of the electrospinning technique, it is also much easier (one single step) to incorporate those essential factors which enhance the regeneration process into the conduits than other methods [35]. Furthermore, it is possible to produce highly aligned electrospun fibers [37], which can provide guidance cues for glial cells (e.g., Schwann cells) growth and subsequent axonal regeneration. 
Table 1. Abbreviations of materials.

\begin{tabular}{llll}
\hline Materials & Abbreviations & Materials & Abbreviations \\
\hline $1,1,1,3,3,3$-hexafluoro-2-propanol & HFIP & Neural stem/progenitor cell & NSPC \\
Acidic fibroblast growth factor & a-FGF & Neurotrophin-3 & NT-3 \\
Adeno-associated viral & AAV & Olfactory ensheathing cell & OEC \\
Adipose-derived stem cell & ADSC & Oxidized cellulose & OC \\
Alpha-1 glycoprotein & $\alpha 1$-GP & Peripheral nervous system & PN \\
Arg-Gly-Asp & RGD & Phosphate buffered saline & PBS \\
Basic fibroblast growth factor & b-FGF & Platelet-derived growth factor & PDGF \\
Bone marrow stromal cell & BMSC & Poly(D,L-lactide) & PDLLA \\
Bone marrow-derived cell & BMDC & Poly(DL-lactide-co-glycolide) & PLGA \\
Brain-derived neurotrophic factor & BDNF & Poly(ethylene oxide) & PEO \\
Cellulose acetate & CA & Poly(lactide- $b$-ethylene glycol- $b$-lactide) & PLA- $b$-PEG- $b$-PLA \\
Central nervous system & CNS & Poly(L-lactic acid) & PLA \\
Dorsal root ganglia & DRG & poly(vinyl alcohol) & PVA \\
Ectomesenchymal stem cell & EMSC & Poly(vinyl pyrrolidone) & PVP \\
Embryonic stem cell & ESC & Polyacrylonitrile & PAN \\
Embryonic stem cell-derived neuronal & ESNPC & Poly( $\varepsilon$-caprolactone) & PCL \\
progentior cell & & & Polyethylene \\
Extracellular matrix & ECM & Polyglycolide & PE \\
Glial growth factor & GGF & Polypyrrole & PGA \\
Glutaraldehyde & GTA & Polyvinyl chloride & PPy \\
Gly-(L-His)-(L-Lys) & GHK & Poly- $\beta$-hydroxybutyrate & PVC \\
Heparin-binding delivery system & HBDS & Sciatic function index & PHB \\
Human Schwann cell & hSC & Skin-derived precursor & SFI \\
Mesenchymal stem cell & MSC & Skin-derived stem cell & SKP \\
Neural growth factor & NGF & Spinal cord injury & SDSC \\
Neuronal progenitor cell & & Vascular endothelial growth factor & VEGF \\
Neural stem cell & & &
\end{tabular}

This review summarizes the development of the electrospinning technique and methods to produce aligned nanofibers for neural regeneration applications (Section 2). Although the scaffold for nerve repair should have sufficient mechanical strength to support tissue development and cell growth, a permanent implant may cause nerve compression. A resorbable implant could avoid this problem. Such a structure should degrade over a controlled period of time at a satisfactory rate at the site of implantation. We discuss the use of biodegradable polymers for electrospinning (Section 3). There has been significant recent work in the area of cell transplantation for injury treatment, and this work forms the basis for cell-seeded engineered structures (Section 4). We survey the improved in vitro cell guidance that is achieved using aligned nanofiber scaffolds compared to random nanofiber mats, and examine the efficacy of cell seeding and/or neurotrophic factor incorporation into implantable structures in enhancing in vitro and in vivo regeneration (Section 5). 


\section{Electrospun Nanofibers}

Nanofabrication methods can be employed to fabricate artificial scaffolds which structurally and biologically imitate the natural ECM at the nano-scale level $[38,39]$. The function of ECM is to maintain and define the structures of tissue and organs, particularly in connective tissue [40]. Sub-micron features of artificial scaffolds are important in increasing cell-scaffold interaction, promoting cell adhesion, and providing topographical cues. In tissue engineering, fibrous scaffolds have gained attention due to features including high surface area-to-volume ratio, alterable porosity, and three-dimensional architecture, all of which favor cellular attachment and growth (for a general review on this subject please see [41-43]). Numerous technologies have been used to produce nano-scale scaffolds, for instance, electron beam lithography [44], colloidal lithography [45], electrospinning [46], chemical etching [47], phase separation [48], and peptide self-assembly [49]. Amongst all these technologies, electrospinning is an exceptionally simple, economical, and widely used method to produce continuous nano-scale polymer fibers in either random or aligned orientation [46,50]. The essential differences between electrospinning and conventional wet/dry fiber spinning reside in the pulling forces and fiber diameters. While conventional spinning processes use mechanical forces to pull and stretch the material to produce fibers ranging from 10 to $500 \mu \mathrm{m}$ in diameter [51], electrospinning uses electrostatic forces to produce fibers ranging from nanometers to a few microns in diameter. Owing to their nature, tissue engineering scaffolds made from electrospun fibers have been successfully produced and demonstrated to mimic ECM in terms of fiber diameter, high porosity, and interconnected architecture (for more information on this subject please see [52-54]).

\subsection{Electrospinning Process}

"Electrospinning", derived from "electrostatic spinning”, regained popularity as a manufacturing technique due largely to emerging interest in nanotechnology around 1994, because it can be easily employed to fabricate fibers from a wide variety of polymers (for detailed reviews on the development of the electrospinning technique please see [55,56]). Huang et al. have reported that nearly 100 different polymers have been electrospun into ultrafine fibers so far from either polymer solution or melt [55]. Srivastava et al. have used microfluidic manifolds to simultaneously spin multiple jets [57] as well as to create core/sheath nanofibers [58].

Figure 1 shows a typical electrospinning setup, which consists of a syringe with a metal needle containing the polymer solution or melt, a metering pump as the feed rate control, a conductive (usually metal) collector, and a high voltage DC power supply. Most setups position the syringe horizontally and use a metering pump to form the polymer droplet. However, the syringe can also be positioned vertically with the collector placed underneath it, and the polymer solution is supplied either through gravity or through a pump [59,60]. Alternatively, the syringe can be mounted at an angle in order to control the flow rate [61]. In the beginning of the process, the metering pump forces the polymer solution or melt to form a pendant polymer droplet held by surface tension at the needle tip. Then an electric field is applied to the system, which induces a repulsion force that opposes the surface tension of the polymer solution or melt [62]. The polymer droplet at the needle tip becomes elongated and deforms into a conical shape, commonly referred to as the Taylor cone [63], as the intensity of the 
electric field increases. The electric field is then increased to a critical value where the electrostatic force is strong enough to overcome the surface tension. A charged polymer jet is ejected from the apex of the Taylor cone, and directed to the oppositely charged collector [62]. The polymer jet is accelerated and stretched by an unstable whipping process with a high whipping frequency [64] due to both external and internal electrostatic forces originating from the charged ions within the polymer jet [65], resulting in decreased diameter and increased polymer jet length [62]. The whipping process facilitates solvent evaporation. Eventually, the dry polymer fiber is deposited on the grounded collector. If the polymer jet is formed from a melt, it solidifies during the flight. Fibers obtained from a polymer melt usually have a larger diameter than those from polymer solution [66-68], and polymer melts must be electrospun in vacuum [69]. The length of electrospun fibers can be as high as several kilometers, since electrospinning is a continuous process [69]. In the cases when it is difficult or impossible to dissolve or melt a polymer for the electrospinning process, a chemical reaction, such as photo-induced polymerization, can be introduced in order to solidify the polymer [70]. Due to the fact that some polymer systems release harmful solvents during the electrospinning process, it is recommended that the process should be performed in a ventilated chamber to permit the exhaust of the solvents.

Figure 1. Schematic of a typical electrospinning setup.

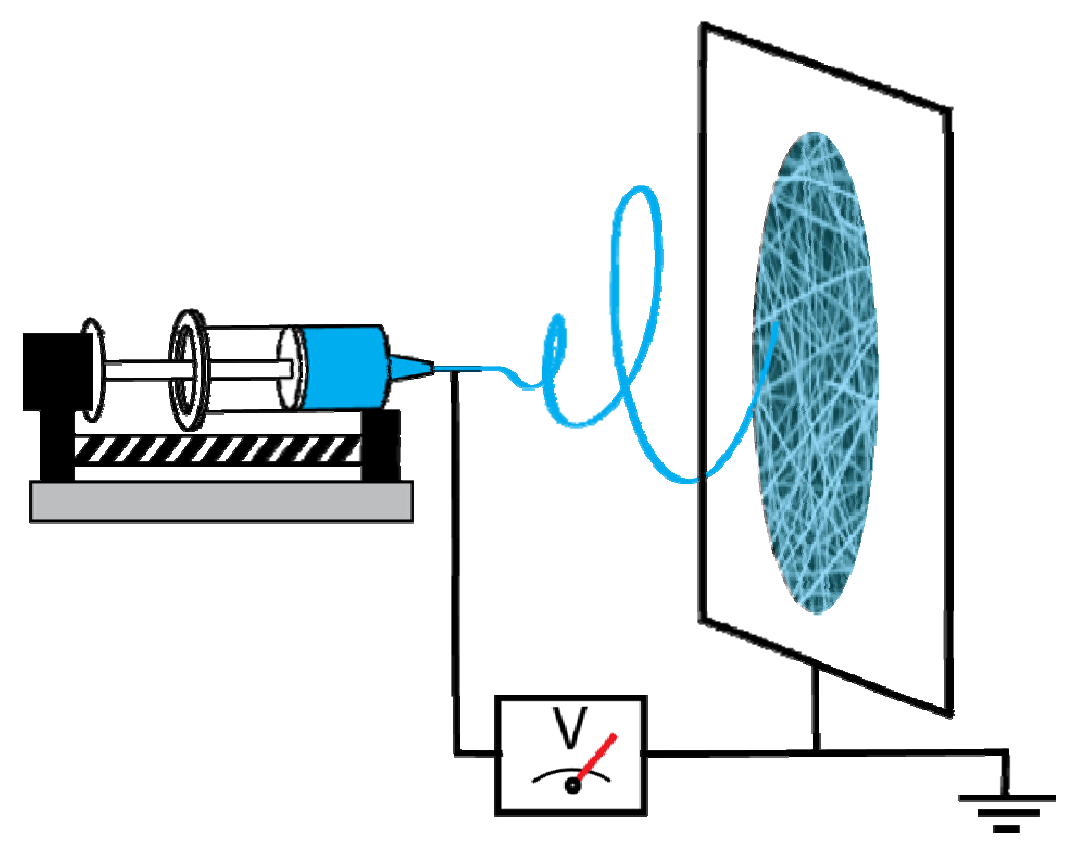

\subsection{Factors Affecting Nanofiber Morphology and Structure}

The morphology and structure of electrospun fibers can be dramatically influenced by a number of variables, including (1) solution properties, such as concentration/viscosity, elasticity, conductivity, volatility of the solvent, and surface tension; (2) processing parameters, such as applied voltage, tip-collector distance, and flow rate; (3) ambient parameters, such as temperature, humidity, and air velocity. The details of the effects of these controllable variables on electrospun fibers have been thoroughly discussed elsewhere [56,71-87]. 


\subsection{Aligned Fibers}

Aligned electrospun polymer fibers play a critical role in better providing topographic cues for neurite outgrowth compared to randomly aligned fibers (please see Section 4 for further discussion). Due to the disordered motion of the polymer jet as it travels from the tip to the collector, randomly distributed non-woven polymer fibers are generally produced with no preferential direction through a typical electrospinning process using a stationary target. Although randomly oriented electrospun fibers have been employed in many applications such as filters [46,88-91], the random orientation may be undesirable in other applications requiring fibers with well-aligned and highly ordered structures, such as microelectronics and photonics and tissue engineered scaffolds for neurite outgrowth [37,50,92]. Therefore, extensive efforts have focused on controlling the fiber architecture and orientation to meet the requirements for such applications.

\subsubsection{Rotating Mandrels}

A number of research teams have used a rotating drum, which replaces the stationary target to collect aligned polymer fibers that are parallel to each other along a common axis [37,93-95]. Edwards et al. investigated the influence of the rotation speed of the collecting drum on the internal and external structures of electrospun polycaprolactone (PCL) fibers [93]. Only partial alignment and little deformation of PCL fibers could be observed when the rotation speed of the drum was slower than the fiber spinning rate (jet velocity). With a higher rotation speed of the drum, mechanical extension of the fibers took place resulting in more alignment. With an even higher rotation speed, the crystals within the fibers became highly oriented due to the deformation of the fibers. However, fracture of fibers and reduction of crystal orientation would occur if the rotation speed passed a threshold [93]. Instead of using a rotating drum with a large width, Theron et al. proposed a much thinner rotating disk with a tapered edge with half angle $\theta=26.6^{\circ}$, a wheel-like bobbin, for collecting continuous aligned fibers around its circumference [96]. The fibers deposited on such a disk were aligned, although the separation between the fibers was not fully uniform, probably because the residual electric charges of the fibers that first reached the disk repelled the following ones [96]. However, it will be difficult to scale up production due to the relatively sharp edge of the collector which gives reduced fiber collection. By creating a gap between two stripes of conductive substrates, such as metals and highly doped silicon, which were then used as the collector, Li et al. were able to generate uniaxially aligned nanofibers from polymers (e.g., poly(vinyl pyrrolidone) (PVP), polystyrene, and polyacrylonitrile (PAN)), ceramics (e.g., $\mathrm{Al}_{2} \mathrm{O}_{3}, \mathrm{Fe}_{2} \mathrm{O}_{3}, \mathrm{NiFe}_{2} \mathrm{O}_{4}$ ), and composites [50]. The width of the gap and the collection time could be altered in order to control the stacking density of the nanofibers [50]. Afifi et al. combined the rotating drum and a two-strip collector to a modified collector consisting of an insulated rotating rotor with several conductive long fins attached to it at equal distance as grounded target points [97]. Continuous poly(L-lactide) (PLA) fibers were wound on the top of the fins as the rotor rotated. However, below a certain tip-collector distance, PLA fibers were either collected in a small quantity due to the repulsive wind force generated from the fins or formed in a bundle due to the insufficient evaporation of the solvent [97]. 


\subsubsection{Parallel Bars}

Due to the uncontrollable chaotic motion of polymer jets, techniques using a rotating drum as the collector generally cannot produce perfectly aligned fibers [98]. Pan et al. then introduced a novel electrospinning technique consisting of two oppositely charged stainless steel needles which were installed tip to tip at a distance of $14 \mathrm{~cm}$ [99]. The polymer (poly(vinyl alcohol) (PVA) or PVP) solutions loaded in the syringes were driven to the needles by a dual syringe pump, and when the electric field was applied, polymer jets were ejected and met in the air forming a neutrally charged yarn of curly fibers, which was then manually towed to a high-speed rotating collector (Teflon tube, aluminum shaft, or plastic cylinder) several centimeters below the meeting point to generate continuously elongated and aligned fibers in a large amount [99]. Substituting the conventional collector material with materials with high relative permittivity, $\varepsilon_{\mathrm{r}}$, can modify the electric field and densify the electrostatic lines of electric flux near the collector [100]. Yan et al. examined a variety of dielectric materials with different $\varepsilon_{\mathrm{r}}$, including epoxy resin $\left(\varepsilon_{\mathrm{r}}=4\right)$, ferrite $\left(\varepsilon_{\mathrm{r}}=12\right)$, water $\left(\varepsilon_{\mathrm{r}}=81\right)$, methanol $\left(\varepsilon_{\mathrm{r}}=25\right)$, and isoamyl alcohol $\left(\varepsilon_{\mathrm{r}}=15.3\right)$, as parallel collectors, and concluded that materials with high $\varepsilon_{\mathrm{r}}$ generally yielded more unidirectional polymer fibers [100]. A threshold value of $\varepsilon_{\mathrm{r}}$, which varies according to different processing conditions, needs to be surpassed in order for aligned fibers to form [100]. Yan et al. also used theoretical simulations to understand the key mechanisms that determined the fiber orientation during the electrospinning process, which showed that the magnitude of the horizontal electric field strength was the chief factor that affected polymer fibers on stretching across the gap between the parallel collectors, and forming aligned fibers afterwards [100].

\subsubsection{Other Strategies for Fiber Alignment}

When a conventional rotating mandrel is used, the polymer jet spreads over the entire length of the mandrel, resulting in relatively poor alignment. Instead of using a conventional conductive collector, Teo et al. proposed a novel electrospinning setup consisting of a non-conductive collector, a high-speed rotating Teflon tube, and a parallel grid of knife-edged aluminum bars below the tube as the counter-electrode [101]. Using this setup they were able to control the deposition of PCL fibers in both the circumferential direction and at an angle to the longitudinal axis of the Teflon tube. Here the polymer jet would spread in a much smaller area (compared to a conventional rotating mandrel) because the parallel aluminum bars concentrated the electric field in the areas of the needle tip and individual strip, resulting in polymer fibers with improved alignment. By tilting the knife-edged aluminum bar through a certain angle, Teo et al. also demonstrated the production of diagonally aligned fibers, as well as a multi-layered patterned tubular laminate composite of fibers in different diagonal directions [101]. Another technique of using auxiliary electrodes to facilitate the formation of aligned fibers was proposed by Lee et al., in which two auxiliary electrodes were introduced: one was a cylindrical electrode attached to the nozzle to stabilize the ejected polymer solution; and the other was a field-controllable electrode producing an alternating current electric field attached to the rotating collector [102]. They were able to obtain aligned PCL fibers with reduced diameter and narrow distribution. In conventional electrospinning process with the rotating collector, the stretching and alignment of polymer fibers is achieved by the high-speed rotating collector; however, in Lee's 
proposed process, stretching and alignment of polymer fibers was due to the field-controllable electrode. Compared with the conventional method, the whipping area during the flight of the polymer solution after ejection was larger, and the fibers underwent a more extensive stretching and alignment process with the introduction of the auxiliary electrodes. Moreover, the alignment of the polymer fibers was parallel to the controllable electrode field direction in the proposed method, as opposed to the conventional method, in which the alignment of the polymer fibers was vertical to the collector rotating direction [102].

Other strategies also have been developed to improve fiber alignment. Badrossamay et al. employed a high-speed rotating nozzle to fabricate 3D continuous polymer fibers, such as PLA, poly(ethylene oxide) (PEO), poly(acrylic acid), etc. [103]. The technique involved a rotating polymer solution reservoir, connected to a motor, with two side wall orifices, surrounded by a stationary cylindrical collector. The ejection of polymer solution toward the cylindrical wall occurred when the combination of hydrostatic pressure and centrifugal pressure surpassed the flow-resistant capillary forces, and the trajectory of the polymer solution jet was warped, attributable to the rotation of the nozzle. It was hypothesized that greater stretching and thinning of the polymer jet that would result in finer fibers would occur with higher centrifugal force [103].

Figure 2 presents the schematics of the aforementioned electrospinning systems. Figure 3 shows an example of aligned electrospun PLA fibers fabricated using a rotating disk.

Figure 2. Schematics of electrospinning systems to produce aligned fibers (adapted from the cited references).

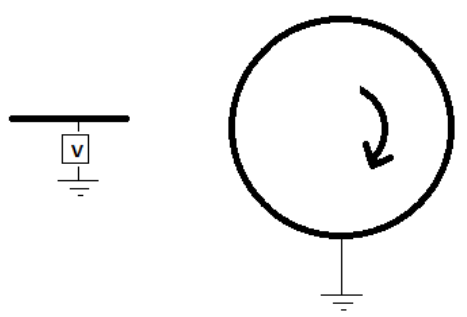

Rotating drum [93]

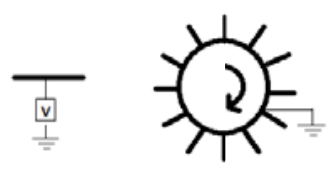

Rotating drum with fins [97]

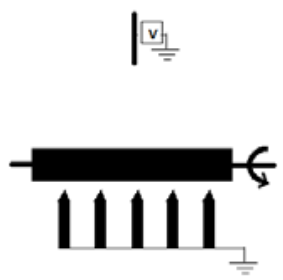

Knife-edged bars [101]

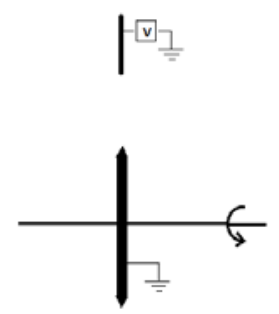

Rotating disk [96]
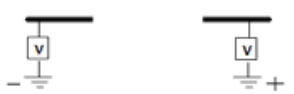

(2)

Opposite needles [99]
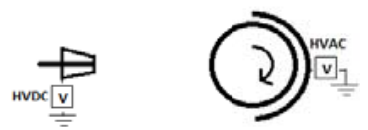
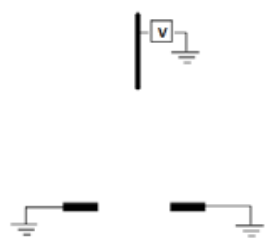

Parallel bars [50]

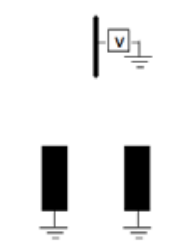

Dielectric materials [100]

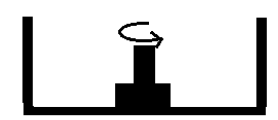

Field-controllable electrode [102] Rotary jet spinning [103] 
Figure 3. SEM image of electrospun poly(L-lactide) (PLA) fibers using a rotating disk. A mixture of DCM/DMF (4/1, wt/wt) was used to dissolve PLA prior to electrospinning. The concentration of PLA solution was $8 \mathrm{wt} \%$. Fibers were electrospun under the conditions of flow rate: $0.8 \mathrm{~mL} / \mathrm{h}$, electric field strength: $29 \mathrm{kV}$ and disk rotation speed: $2,500 \mathrm{rpm}$.

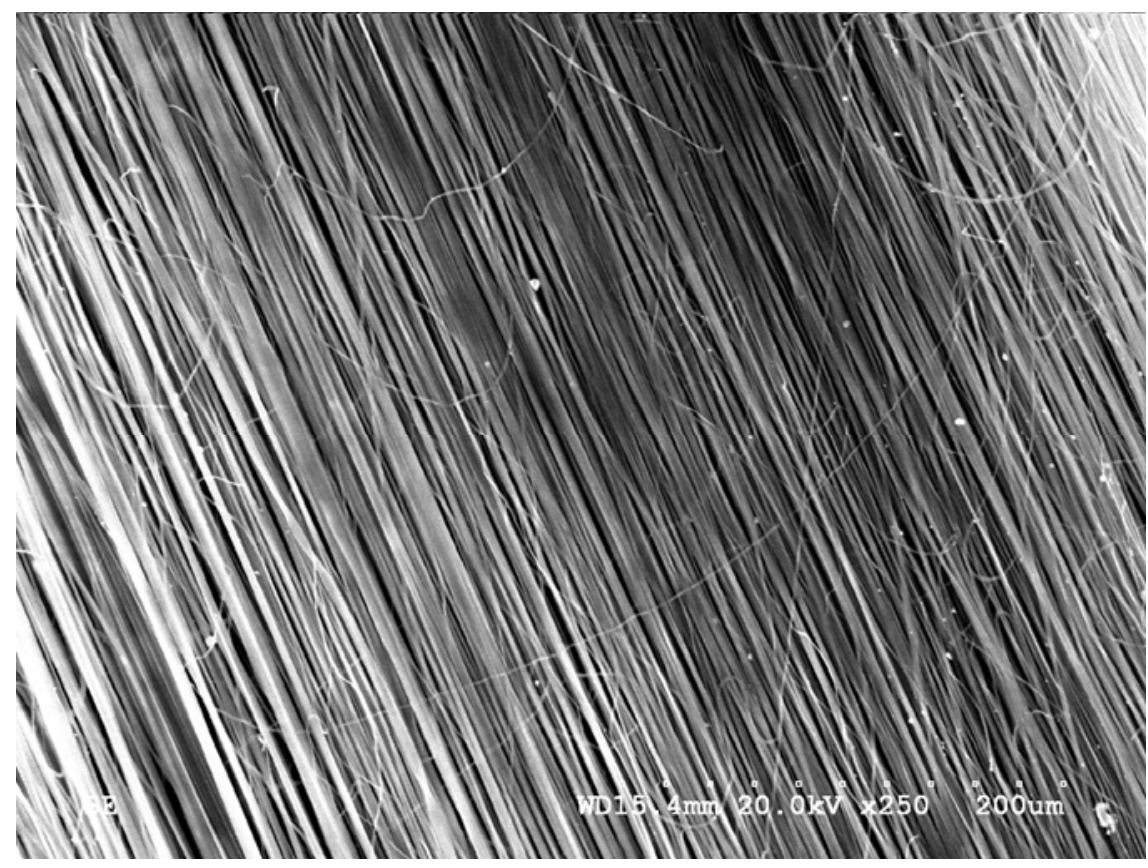

\section{Biodegradable Polymers}

A biodegradable conduit could support tissue regeneration, and would not require a second surgical procedure to remove the structure when the regeneration is complete. If the scaffold were not removed, it might compress the tissue or cause chronic irritation. Biodegradable polymers can be derived from natural sources or may be synthesized. Natural biopolymers, derived from naturally existent materials (e.g., chitin and chitosan from crustacean shells; cellulose from wood, etc.), are renewable resources and possess better inherent biodegradability, biocompatibility, biofunctional motifs, and lower immunogenicity than synthetic polymers [104-110]. They have thus been widely used in many biomedical applications. There are two major categories of common natural biopolymers that have been successfully electrospun into ultrafine fibers: polysaccharide and protein [111].

\subsection{Polysaccharide Nanofibers}

Cellulose is the most abundant, naturally occurring biodegradable polymer on our planet [112]. It is difficult to electrospin cellulose using common organic solvents due to its strong inter- and intra- molecular hydrogen bonds [113]. Kim et al. used a lithium chloride/N,N-dimethylacetamide solvent system to dissolve cellulose, and they obtained amorphous cellulose fibers with diameters ranging from 150 to $500 \mathrm{~nm}$ [114]. Another solvent system, N-methylmorpholine oxide and water, was also used to prepare electrospun cellulose solution [115]. Cellulose acetate (CA), a derivative of cellulose, has also been electrospun into ultrafine fibers using acetone or acetone/water as solvent $[46,116]$. Compared to cellulose, a CA solution is more easily prepared for electrospinning due 
to its solubility. Ma et al. electrospun CA fibers with enhanced structural and mechanical properties with 1-h heat treatment at $208{ }^{\circ} \mathrm{C}$ [116]. Son et al. produced ultrafine oxidized cellulose (OC) fibers from electrospun CA fibers by subsequent deacetylation and oxidation processes [117]. Han et al. applied electrospun OC fibers as metal chelators for absorbing heavy metal ions from polluted groundwater in environmental remediation technology [118]. Additionally, electrospun CA fibers have also been used in cosmetics [119], drug delivery [120], protein detection [121], bactericide [122], and bio-scaffolding [46] applications. Chitin is the second most abundant naturally occurring polysaccharide after celluose, and it can be readily obtained from the shells of arthropods, such as crabs and insects [123]. Noh et al. [124] and Min et al. [125] successfully electrospun chitin in 1,1,1,3,3,3-hexafuoro-2-propanol (HFIP) with the aid of irradiation to improve its otherwise poor solubility. Noh et al. demonstrated the potential use of electrospun chitin fibers in wound dressing or tissue engineering scaffolding due to their distinctive biological features, including wound healing effects, biocompatibility and biodegradability [124]. Chitosan is the $\mathrm{N}$-deacetylated derivative of chitin, and has been prepared in aqueous acidic solvents, such as acetic acid [126], trifluoroacetic acid [127], and formic acid [127], as the as-spun solutions. Geng et al. obtained electrospun chitosan fibers with an average diameter of $130 \mathrm{~nm}$ from a $7 \%$ chitosan solution in a 90\% aqueous acetic acid solution, and investigated the effects of several parameters of both solution and process on the structure and morphology of the fibers [76]. They discovered that acetic acid concentration was the most important factor, and it decreased the surface tension of the solution and simultaneously increased the charge density of the polymer jet. The morphology of beaded fibers evolved into homogeneous fibers with increasing acetic acid concentration [76]. In addition to electrospinning pure chitosan fibers, blends of chitosan and PEO [128], chitosan and PVA [129], chitosan and poly(ethylene terephthalate) [130], chitosan and nylon-6 [131], and chitosan and poly(L-lactic acid-co-epsiloncaprolactone)) [132] have also been successfully fabricated via electrospinning.

\subsection{Protein Nanofibers}

As fundamental building blocks of life, protein fibers play a large role in scaffolding, motility, elasticity, protection of cells, stabilization, tissues and organisms (for an extensive review please see [133]). Collagen, the most abundant protein in the human body and the key structural element of ECM of many tissues, is resorbable, has high water affinity and low antigenicity, provides structural and mechanical support to tissues, sequesters tissue maintenance and regeneration factors, transmits forces, dissipates energy, and provides biological signals to adjacent cells [134-136]. Collagen types I, II and IV have been successfully electrospun into ultrafine fibers using either HFIP [38,137-139] or phosphate buffered saline (PBS)/ethanol $(\mathrm{pH}=7)$ [140] as solvent. However, HFIP may not be a desirable solvent for fabricating electrospun collagen scaffolds for tissue engineering applications due to its toxicity and corrosiveness as well as the fact that collagen which has been electrospun from HFIP may lose its natural conformation [140,141]. Therefore, the PBS buffer/ethanol solvent system seems to be an alternative for electrospinning collagen with the application in tissue engineering. Fibers of blended collagen and other components, such as PEO [142], PCL [143], chitosan [144], polyurethane [145], and polydioxanone (PDO) [146], have also been prepared by electrospinning. Synthesized by the liver, fibrinogen is an important protein to the coagulation of blood [135]. 
Wnek et al. electrospun human or bovine fibrinogen fraction I in a minimum essential (Earle's salts)/HFIP solvent into fibers with diameters ranging from 80 to $700 \mathrm{~nm}$ [147]. In addition to potential uses in cartilage repair [148], wound healing and drug delivery [149], electrospun fibrinogen fibers can also be used in tissue engineering scaffolds [150].

\subsection{Biodegradable Synthetic Polymer Nanofibers}

In addition to polysaccharides and proteins, many synthetic polymers also possess relatively good mechanical, biocompatible and biodegradable features. Amongst these, the degradation behavior of a number of polyesters, including polyglycolide (PGA), poly(L-lactide) (PLA), and their copolymer poly(D,L-lactide-co-glycolide) (PLGA) have been extensively studied. You et al. investigated the degradation rates of electrospun PGA, PLA and PLGA nanofibers in PBS solution in incubation at $37^{\circ} \mathrm{C}$ [151]. The mechanism of the degradation of aliphatic polyesters is through hydrolysis of the ester backbone [152,153]. The degradation rate of PLGA was slow in the first 25 days, and accelerated afterwards, and the residual weight was below 50\% after 45 days, while PGA, however, had a rapid degradation rate in the first 20 days, and the residual weight was about $40 \%$ at day 20 . Compared with PGA and PLGA, PLA had a much slower degradation rate [151]. Hurrell et al. proposed a 4-stage degradation mechanism for PGA [154]. In stage I, water diffuses throughout the polymer, followed by stage II, in which homogeneous hydrolysis occurs, and at the same time the polymer crystallizes through insertion crystallization. Chain cleavage and water plasticization contribute to this crystallization process. When the molecular weight reaches a critical value, which commences stage III, oligomers begin to diffuse from the surface, where a reaction-erosion front is formed. Subsequently in stage IV, the front may move through the sample and encounter the other front formed from the opposite surface [154]. Zong et al. [155] also described a four-stage process for structure and morphology changes during PLGA degradation. Since the glass transition temperature of the electrospun fibers was $38{ }^{\circ} \mathrm{C}$ and the degradation was carried out at $37{ }^{\circ} \mathrm{C}$, they found thermally-induced crystallization in the electrospun fibers after 1 day of incubation [155].

The degradation rate of polymers can also be different between the bulk materials and the electrospun fibers (for detailed reviews please refer to [156]). For some polymers, the degradation rate of larger structures is faster than that of nanofibers due to autocatalysis in larger structures.

The degradation rate of a scaffold will also be modified in the presence of cells as compared to incubation in a buffer solution. Dong et al. [157] found that the degradation rate of PLGA nanofibers was accelerated when cultured with smooth muscle cells due to increased surface erosion. Pan et al. [158] used a co-culture of fibroblasts and macrophages to study cell-mediated degradation. They found upregulation of lysozyme, non-specific esterase, other enzymes, as well as two cell surface receptors. The co-culture showed faster degradation than monoculture or degradation without cells.

A slow biodegradation rate of PLA is observed even in the non-crystalline form, poly(D,L-lactide) (PDLLA), the enantiomeric semicrystalline forms, poly(D-lactide) and PLA [159]. In order to address the issues of long degradation time, hydrophobicity and mechanical stiffness of PLA, Kim et al. fabricated an electrospun scaffold consisting of fine fibers from a blend of PLA, PLGA random copolymer, poly(lactide- $b$-ethylene glycol- $b$-lactide) (PLA- $b$-PEG- $b$-PLA) triblock copolymer, and a lactide [159]. Through copolymerization, structurally similar yet faster degrading glycolide 
components, such as PLGA, could be incorporated into the PLA polymer chains resulting in a faster degradation rate of PLA [160]. Lactide rapidly converts into lactic acid in an aqueous environment, thus it was used as a hydrophilic catalyst to accelerate the hydrolytic reaction, though the amount of lactide could not be too high since it would compromise the mechanical strength and acidify the scaffold [159]. The triblock copolymer PLA- $b$-PEG- $b$-PLA was physically blended into the system in order to modify the hydrophobicity of PLA as well as slow the diffusion rate of the lactide [159]. The in vitro degradation study showed that the scaffold lost $65 \%$ of its original mass in 7 weeks, significantly higher than pure PLA [159]. Kim et al. also measured the contact angle on the nanofiber mats and found that the hydrophobility of the scaffold decreased from $105^{\circ}$ (pure PLA scaffold) to $50^{\circ}$ [159].

Due to the nature of degradation process of polyesters, there are some challenges that still need to be addressed when using aligned electrospun polyester fibers for tissue engineering applications. Jiang et al. reported that electrospun PLGA membranes shrank to $20 \%$ of its original area after incubation at $37^{\circ} \mathrm{C}$ in PBS for $2 \mathrm{~h}$ [161]. The morphology of the fibers also changed from smooth and straight in the original membrane to coiled and wavy in the shrunken mat [161]. Li et al. also reported a similar shrinking phenomenon in addition to fiber swelling and fusion in electrospun polyester scaffolds during incubation at $37{ }^{\circ} \mathrm{C}$ in PBS [162]. Efforts are currently underway to mitigate these undesirable effects.

Another challenge when using PGA or PLGA as the implant material for treating tissue damage/loss is that their degradation products, although metabolically resorbable, can potentially increase the acidity of the local environment which may cause unfavorable foreign-body reactions, such as an inflammatory response, resulting in cellular death [163,164]. Clinically, surgical drainage at the implantation site has been applied to successfully settle such reactions [163]. Alternatively, it has been suggested that the application of basic salts might be able to offset the decreased $\mathrm{pH}$ caused by the degradation products [165]. In addition, inhibition of $\mathrm{C} 5 \mathrm{a}$ could also offer a therapeutic intervention to impede the inflammatory reaction [164].

Bini et al. [166] fabricated a tubular and porous nerve guidance conduit made of PLGA (10:90) fibers using a microbraiding technique with potential application for peripheral nerve regeneration, and also investigated its degradation behavior. Swelling, a common phenomenon caused by water uptake and observed in many biodegradable nerve conduits, was not detected; maintaining a constant lumen cross section in a conduit may be advantageous for nerve regeneration. Degradation occurred in the form of fiber breakup due to bulk hydrolysis. Figure 4 shows images of the PLGA conduit and its micro-scale features.

Compared with other biopolymers, PCL has a longer degradation time [167] and good mechanical properties [168], and has been so far employed for biomedical applications, such as bone regeneration [169,170], drug delivery [171], nerve tissue regeneration [172,173], wound dressing [174], and gene delivery [175]. Pektok et al. were among the first to evaluate the in vivo degradation and healing features of small-diameter vascular grafts consisting of electrospun PCL fibers with a mean diameter of $1.90 \mu \mathrm{m}$ in the rat systemic arterial circulation [176]. The major mechanism of PCL degradation is the breakup of ester linkages by nonenzymatic random hydrolysis [177]. The main cause for failure of graft using biodegradable polymers was aneurismal dilatation due to the premature loss of mechanical strength of the graft material [178]. Pektok et al. examined the weight loss by assessing the molecular weight changes of the PCL grafts and discovered $20 \%$ loss for $\mathrm{M}_{\mathrm{w}}$ 
(weight average molecular weight, $\mathrm{M}_{\mathrm{w}}=\sum_{i} N_{i} M_{i}^{2} / \sum_{i} N_{i} M_{i}$, where $\mathrm{N}_{\mathrm{i}}$ is the number of moles of each polymer species and $\mathrm{M}_{\mathrm{i}}$ is the molar mess of the species) and $22 \%$ loss for $\mathrm{M}_{n}$ (number average molecular weight, $\left.\mathrm{M}_{\mathrm{n}}=\sum_{i} N_{i} M_{i} / \sum_{i} N_{i}\right) 24$ weeks after implantation, and observed no significant premature structural deformities and thus no aneurismal dilatation [176].

Figure 4. (A) Macrographs of poly(DL-lactide-co-glycolide) (PLGA) conduits; (B) SEM image of the PLGA conduit; (C) SEM image shows the average pore size of the conduit; (D) SEM image shows the braiding angle of the conduit. Reprinted from [166] with permission from John Wiley and Sons.

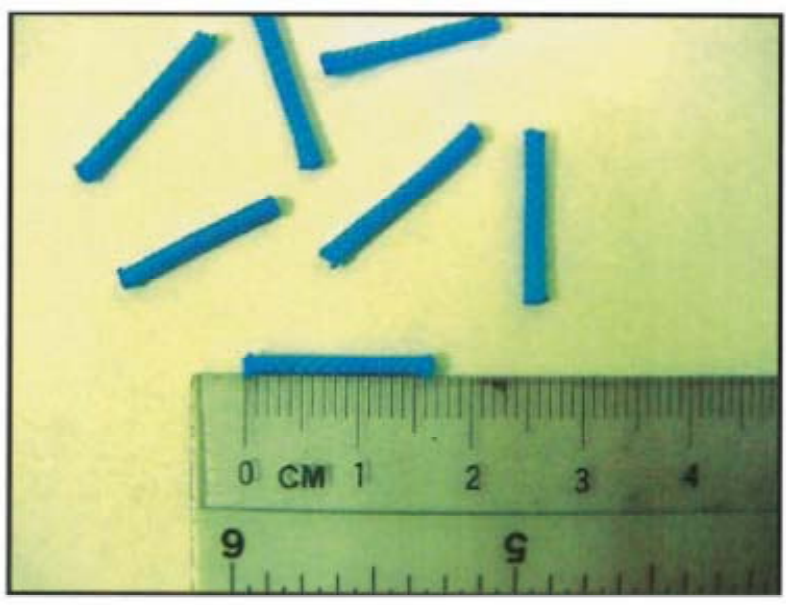

(A)

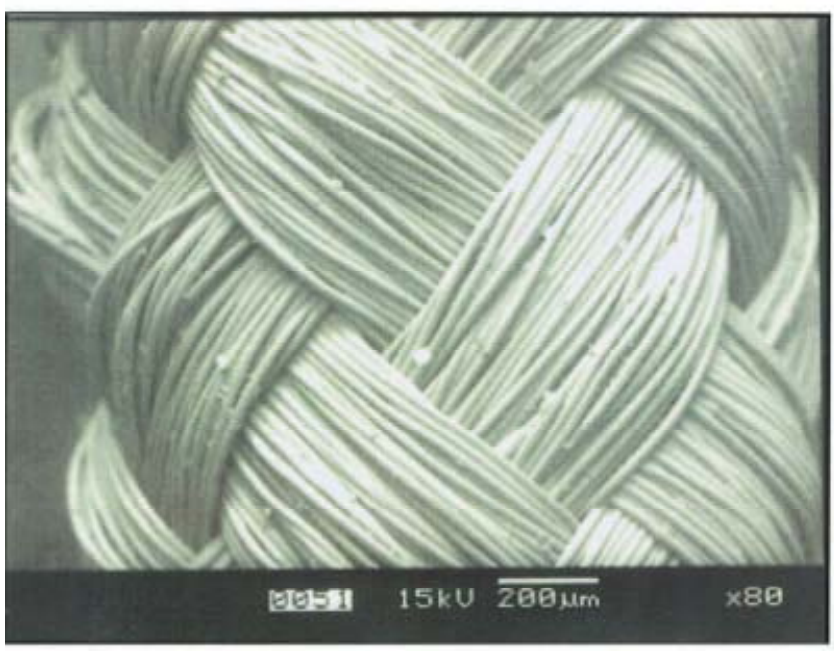

(B)

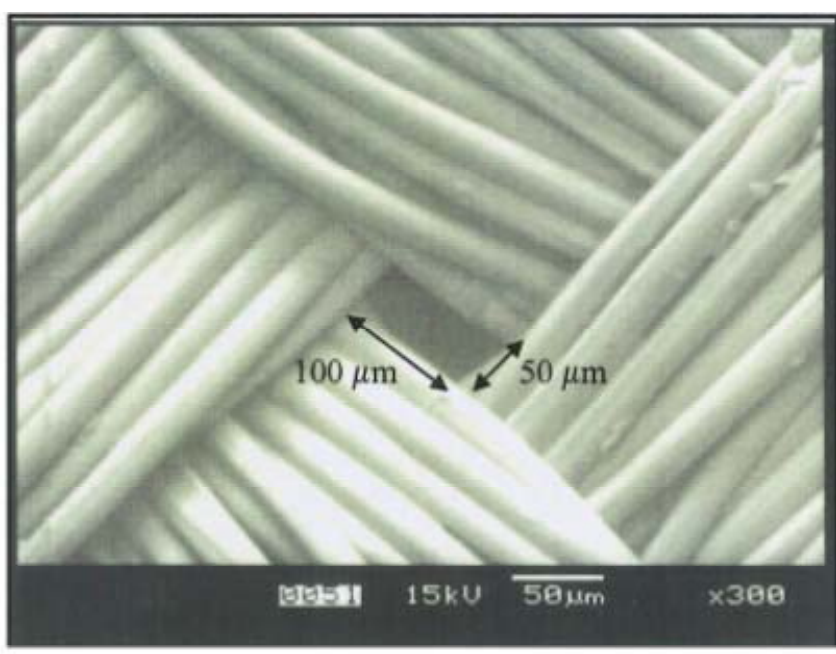

(C)

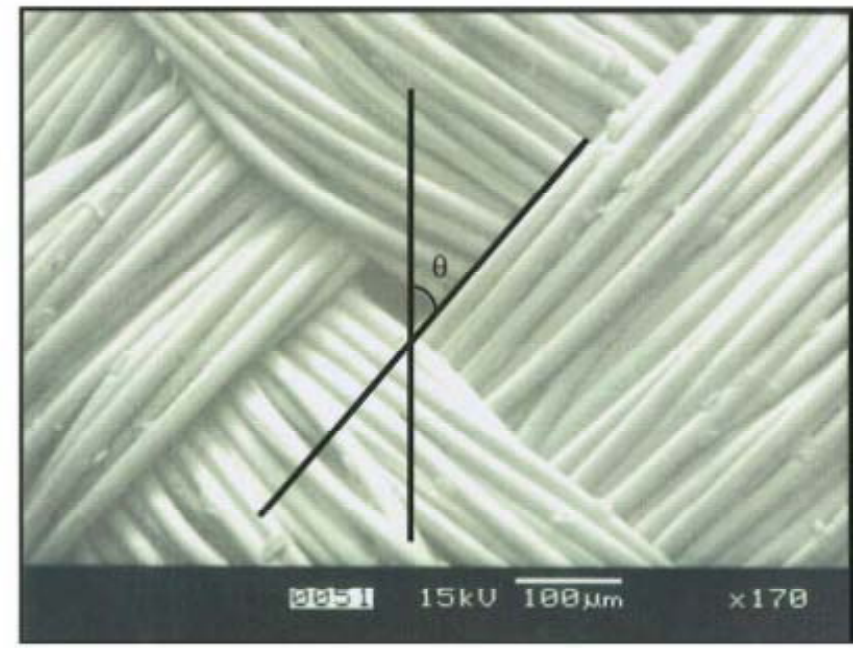

(D)

\subsection{Permissive Environment for Regeneration: Collagen, Laminin, and Fibronectin}

Extensive research has been conducted for over a century to identify an ideal growth medium for axonal regeneration. As mentioned in Section 2, the natural ECM, consisting of various proteins (collagen, laminin, fibronectin) and polysaccharides, significantly affects neural regeneration [179]. Through the interaction with its ECM, cell activity is regulated for morphogenesis, maintenance, and 
adaptation purposes [180]. Collagen is known to promote cell proliferation, possess good affinity with the living body, generate minimum scar tissue, and cause little inflammatory response or immunological reaction [181,182]. Rosen et al. used a biodegradable and flexible conduit made of glycolide trimethylene carbonate (GTMC) filled with a collagen matrix to bridge a relatively short nerve gap of $5 \mathrm{~mm}$ of a rat peroneal nerve, and concluded that the outcome from the artificial conduit was similar to the one from autografts in terms of organization and reaction at the graft site, quantitative physiology, axon diameter and toe spread analysis [179]. However, statistically, the axon count in the autografts was significantly higher than inthe artificial conduit [179]. Clinically, the peripheral nerve injury gap is usually larger than $5 \mathrm{~mm}$; therefore, research on bridging a wider gap would provide more useful information.

Figure 5. (a) SEM image of polyglycolide (PGA)-collagen nerve conduit filled with collagen sponge and (b) the intraoperative view of the conduit after implantation. Reprinted from [181] with permission from Elsevier.

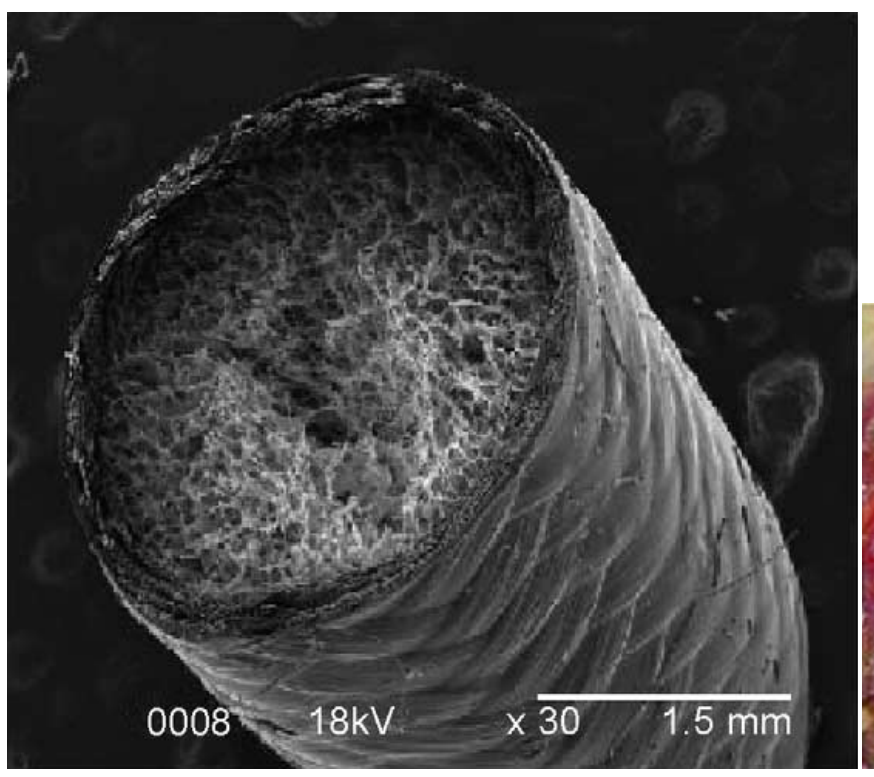

(a)

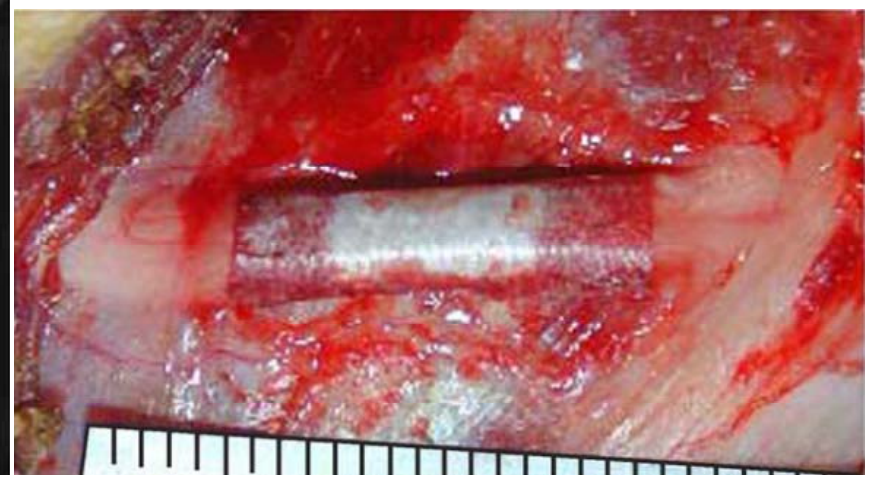

(b)

Using a tubular braiding machine, Nakamura et al. were able to produce a PGA conduit with a hydrophilic surface through plasma discharge treatment, and subsequently coat the inner wall of the conduit with a layer of amorphous collagen and used this PGA-collagen conduit to bridge a 15-mm peroneal nerve gap in beagle dogs [181]. Figure 5 shows the SEM image of the PGA-collagen nerve conduit filled with collagen sponge and the intraoperative view of the conduit after implantation. The PGA-collagen conduit outperformed autografting in terms of functional recovery 6 months after surgery, and thus it was suggested that this collagen sponge could be a potentially effective alternative for repairing some neural defects [181]. Instead of a collagen sponge, Okamoto et al. used longitudinal collagen filaments with a diameter of $50 \mathrm{~nm}$ to fill up a collagen tube to bridge a nerve defect of $30 \mathrm{~mm}$ in the peroneal nerve of a Beagle dog model [182]. Functional recovery was observed within 52 weeks after the implantation surgery [182]. Collagen can be crosslinked by a number of crosslinking agents, such as glutaraldehyde (GTA), formaldehyde, and epoxy compounds, and can be 
functionalized to bind with bioactive peptides to promote cell proliferation [183]. Ahmed et al. crosslinked collagen conduits by two methods: microwave irradiation (MWI) and crosslinking agent GTA, and subsequently bound the conduits with bioactive peptides, Arg-Gly-Asp (RGD), Gly-(L-His)-(L-Lys) (GHK) and biotinylated-GHK. The mechanical tests showed that the crosslinked collagen conduits were more elastic than uncrosslinked ones, which increased the survival rate of the conduits during and after implantation surgery. The results from in vivo studies on bridging a 10-mm sciatic nerve gap in Wistar rats revealed that fibrin matrix filled the crosslinked conduits 10 days after surgery, and a thin cable emerged to connect the proximal nerve stump to the distal end in crosslinked conduits after 1 month compared with the uncrosslinked control group, in which fewer cells (mostly fibroblasts) grew [183].

Laminin, an abundant basement membrane-specific macromolecule, is known to promote neurite regeneration and guide neurite outgrowth, and is used as either a standalone substrate or a stimulatory agent for axonal regeneration [184-188]. Yoshii et al. [189] coated nerve guides made of polyester filaments with laminin to repair a 10-mm rat sciatic nerve defect. After 4 weeks, they found that both myelinated and unmyelinated axons were among the polyester filaments in most of the guides tested, while no axon was observed in the control group. The laminin used in this work was derived from a different species, and therefore it was suggested that laminin derived from one species could be used in directing neural regeneration of another species [189]. Laminin can also act as a stimulatory agent. Madison et al. [190] filled a nerve guide made of PDLLA containing laminin and other ECM components to bridge a 4 to $5-\mathrm{mm}$ rat sciatic nerve gap, and the result showed that laminin considerably accelerated axonal regeneration in vivo [190]. Koh et al. [191] also measured the efficacy of laminin-PLA nanofibers on enhancing axonal extensions using a rat sciatic nerve defect model and discovered that laminin-modified PLA nanofibers showed better results than unmodified PLA nanofibers in terms of neurite extension, cell viability, attachment and proliferation [191].

Another important ECM protein, fibronectin, has also been studied and demonstrated to be capable of promoting peripheral nerve regeneration and preventing invasion by fibroblasts $[192,193]$.

In summary, biodegradable polymers can be formed into scaffolds which support and guide the regeneration of axons. Although PLA, PGA, and PLGA have been the most widely used materials, the acidic byproducts of their degradation can lead to undesirable inflammation at the injury site and disorganized axon growth. Thus, the development of new, electrospinnable polymers which may also have tunable degradation rates may be required. These new polymers may also be modified through covalent linkage of peptides or incorporation of growth factors to improve axonal regeneration and remyelination. Burst release of molecules such as growth factors incorporated within the polymers can be avoided by judicious choice of compatible solvent for electrospinning. The growth factors can also be loaded within the core of coaxial fibers for more sustained release.

\section{Cell Transplantation and Cell-Seeded Constructs}

Investigation of cell transplantation as a treatment for SCI has involved several cell types, including Schwann cells, olfactory ensheathing cells (OECs), neural stem cells (NSCs), neural progenitor cells (NPCs), neural and glial precursors, and bone marrow stromal cells (BMSCs) (for a systematic review of cell transplantation please refer to [194]). These cells have the potential to remyelinate neurons, 
guide axon growth, and secrete trophic factors which can promote plasticity or have neuroprotective effects. The cells have typically been injected at the injury site through syringes or capillaries, 1 to 2 weeks after injury. Of these cell types, Schwann cells have been the most studied. Although Schwann cells themselves are able to enhance regeneration of axons of dorsal root ganglia (DRG) or propriospinal axons in the vicinity of the injury, they have not been shown to promote significant brainstem spinal axonal regeneration.

\section{The Need for Cell-Seeded Constructs}

Schwann cells alone have been unable to guide regenerating axons beyond a graft site to reenter the host spinal cord ("off-ramp") [195]. Thus, a combination strategy involving both engineered and cellular components may enhance regeneration across peripheral nerve gaps or SCI sites. The engineered nanofiber scaffold will help regenerating nerve fibers to cross the gap through topology which is more growth permissive. This scaffold will also be seeded with cells which support the regenerating nerve fibers. A significant amount of recent work has examined cell transplantation, as well as cell seeding into hydrogels scaffolds or conduits, for treatment. The results from this work will guide the further development of cell-seeded nanofiber scaffolds.

\subsection{Schwann Cells}

A supportive microenvironment is critical for neurite regrowth. Schwann cells, the principal glia cells of PNS, facilitate both peripheral and central nerve regeneration by providing a permissive environment. Shortly after injury, Schwann cells divide rapidly, move to the injury site, express a completely different set of genes, and stimulate axonal regrowth, the key element in functional restoration of nerves at the early stages [196-202]. In response to axonotmesis injury, in which the axon is injured but the myelin sheath remains intact, Schwann cells form aligned paths, termed bands of Büngner, which guide regenerating axons in peripheral nerves [200]. Neurite outgrowth has been reported to be directed by Schwann cell alignment, possibly through the topography of the monolayer of Schwann cells and the adhesion molecules and ECM components expressed on their surface, when other guidance cues are absent [203]. Schwann cells produce various neurotrophic factors, including NGF, BDNF and ciliary neurotrophic factor, express cell adhesion molecules which increase glia-neuron interactions, and release other molecules which influence regenerating axons [199,200]. In addition, Schwann cells can also synthesize ECM components that facilitate neuron regeneration [204].

$\mathrm{Xu}$ et al. studied the efficacy of using a Schwann cell-seeded PAN/polyvinyl chloride (PVC) mini-channel on repairing a hemisected adult rat spinal cord [205]. One month post-surgery, a tissue cable was observed in Schwann-cell seeded channel with significantly more myelinated axons and blood vessels, and larger cross sectional area than the control group without seeded cells. The growth of supraspinal fibers from 19 other brainstem areas was observed in the Schwann-cell seeded mini-channels in addition to that of propriospinal axons and axons of PNS origin. Furthermore, a subpopulation of the regenerated axons was also observed to have penetrated the distal interface and re-entered the grey matter, a phenomenon that did not occur in the control group. Cultured Schwann cells were demonstrated to have survived in the distal host environment and promoted 
the axonal regrowth [205]. Novikova et al. evaluated the influence of a Schwann cell-seeded poly- $\beta$-hydroxybutyrate (PHB) conduit with a unidirectional fiber orientation on axonal regeneration after cervical SCI in rats [206]. The cell-seeded PHB fibrous conduit supported Schwann cell attachment and proliferation and enhanced axonal regeneration. Although the addition of ECM molecules, such as fibronectin, was demonstrated to have improved cell survival in vitro, they were found to be unsuccessful in supporting neuronal survival and promoting axonal growth [206].

Blits et al. [207] fabricated a Schwann cell bridge by inserting a mixture of Schwann cells, fibrinogen, gentamicin and aprotinin into a PAN/polyvinyl chloride (PVC) and investigated its efficacy on repiring SCI. Adeno-associated viral (AAV) vectors encoding for BDNF (AAV-BDNF) and (AAV-neurotrophin-3 (NT-3)) were administered in two experimental groups respectively to evaluate their effect on improving hind-limb function. A significant but modest improvement in function recovery of hind-limb was observed in both AAV-BDNF and AAV-NT-3 treated rats, compared with the control group.

Guénard et al. [208] used Schwann cell seeded permselective guidance channels consisting of a $\mathrm{PAN} / \mathrm{PVC}$ copolymer tubing to repair an $8-\mathrm{mm}$ rat sciatic nerve gap. The Schwann cells were able to form an aligned cable in the channels and enhance the axonal regeneration process in PNS. The density of Schwann cells in the synthetic guidance channels played a central role in the outcome of regeneration. The myelinated axon counts were significantly larger in channels seeded with Schwann cells with higher density than those with lower density [208]. Keeley et al. [202] compared Schwann cell seeded conduits with collagen-filled conduits for peripheral nerve regeneration using a rat model. They found that the Schwann cells improved peripheral nerve regeneration as assessed using histology, electrophysiology, and walking track analysis [202]. As shown by Williams et al. and others [196-202], Schwann cells may have an impact on peripheral nerve regeneration in the early phases. Bryan et al. [197] investigated this "early impact" by bridging a 20-mm, a fairly long, nerve gap in a rat model by using a poly-L-lysine precoated polyethylene (PE) guide filled with pre-established Schwann cells. Cell-seeded guides had better results in axon counts and nerve conduction velocity. The positive impact of Schwann cells on the repair process might be due to the directing cue that Schwann cells provided [197]. Rodriguez et al. [209] investigated the influence of syngeneic (genetically identical), isogeneic (genetically alike) and autologous Schwann cells, respectively, on peripheral nerve regeneration using a mouse model. The regeneration process aided by autologous Schwann cell-seeded conduit showed the best result and a similarity to one with an autologous nerve graft. Isogeneic Schwann cell-seeded guides gave a lower recovery result, while syngeneic Schwann cells did not appear to enhance the regeneration process [209]. Lohmeyer et al. [210] filled a collagen conduit with polyglactin (a synthetic absorbable polyester commonly used as suturing material) filaments seeded with Schwann cells and isogenic Schwann cells suspended in Matrigel and used it to repair a $20-\mathrm{mm}$ sciatic nerve gap in a rat model. Although the number of myelinated axons, which crossed the gap to reach the distal stump, was significantly greater in the Schwann-cell seeded conduits than those in unseeded ones, the number of regenerated axons was still insufficient to regain the motor function. This might be due to granuloma formation or the foreign body reaction caused by degraded polyglactin filaments, which either physically hindered the regeneration process or adversely affected cell function [210]. Ishikawa et al. examined the effect of chitosan gel sponges containing 
BMSC derived Schwann cells on peripheral nerve regeneration using a rodent model and concluded that the Schwann-cell seeded chitosan sponge could be a good potential candidate for neural repair [211].

\subsection{Neural Stem Cells}

Although they have shown great potential for enhancing neural regeneration, Schwann cells unfortunately have some disadvantages when applied in cell therapy. First, it is difficult to have access to nerve donor to harvest sufficient Schwann cells [212,213]. Second, it is time-consuming to culture and expand Schwann cells in vitro, which may therefore delay treatment [214].

NSCs are cells that can differentiate into other types of cells, such as astrocytes, neurons, and oligodendrocytes, and also are able to self-proliferate [215]. Transplanted NSCs were reported to enhance axonal regeneration through a chronically denervated nerve [216]. The mechanism for the NSCs-induced improvement for axonal regeneration might be that NSCs secreted both metalloprotease-2, a matrix which degraded chondroitin sulphate proteoglycans, an inhibitory ECM component, and numerous neurotrophic factors [216].

Teng et al. designed an implantable double-layered polymer scaffold, consisting of a porous layer seeded with NSCs as the inner portion which mimicked the gray matter and a long, axially oriented porous layer as the outer portion which mimicked the white matter, for treating hemisected SCI in adult rats [217]. With regard to the recoveries of motor function and sensory responses, NSC-seeded scaffold and scaffold alone groups outperformed NSCs alone and lesion control groups, with NSC-seeded scaffold showed the best improvements. Six months post injury, scar formation was absent in the groups treated with scaffolds both with and without seeded cells. In contrast, scar tissue and cysts were apparent in cell-alone and lesion control groups. Although the mechanism of the scaffold remained unclear, they hypothesized that the scaffold hindered the formation of scarring and cyst, which might be due to the fact that the outer portion of the scaffold inhibited cellular ingrowth. The primary reason for improved functional recovery in cell seeded group was probably due to tissue preservation. The role of NSCs in functional recovery could possibly be trophic support [217].

The effect of NSCs and Schwann cells on axonal regeneration was studied by Olson et al. [218]. They fabricated a multi-channel PLGA scaffold seeded with either NSCs or Schwann cells and implanted in the transected spinal cord of rats. Both NSC- and Schwann cell-seeded scaffold treated groups showed greater axonal counts than the unseeded control group, with the Schwann cell seeded scaffold treated group having the most axonal counts, although the absolute numbers of axonal counts of all groups were relatively small compared with that of normal spinal cord. They found no significant difference in locomotor function recovery in all groups [218].

Most SCI treatment experiments have been performed on rats, which have significantly different genetic background from humans [219]. Therefore, it is crucial to use animal models that share similar neuroanatomical and neurophysiological structures to humans to corroborate the results which have been obtained in rodent SCI models [219]. Lee et al. used a canine SCI model to examine the effects of human NSCs on treating SCI and found positive results in terms of functional recovery [219]. Pritchard et al. studied the efficacy of using an African green monkey model on testing NSC-seeded polymer scaffold for SCI treatment [220]. Although the results did not provide statistical assessment of the cell-seeded scaffold for treating SCI due to limited sizes of the tested groups, this primate model 
may be used to overcome the problem of spontaneous recovery from SCI often observed in rodent models [220].

\subsubsection{Neural Progenitor Cells}

Similar to stem cells, NPCs can differentiate into different cell types, but they are more specific cells than stem cells and differentiate into their target types.

Zahir et al. implanted a neural stem/progenitor cell (NSPC)-seeded laminin-coated chitosan tube at a completely transected spinal cord in a rat model [221]. Five weeks post-surgery, NSPCs were found to have survived and differentiated into astrocytes and oligodendrocytes, and a thick tissue cable was also formed between the severed rostral and caudal stumps in the tube. This demonstration showed a promising employment of chitosan tubes for delivering NSPCs and repairing SCI [221]. The same group subsequently compared the results from treating subacute SCI in a rat model by either injecting adult rat spinal cord-derived NSPCs directly or transplanting NSPC-seeded uncoated chitosan channel to the lesion site [222]. Although the progenitor features of the cells retained, the survival rate was lower than the one that was found in the first study. However, the survival of NSPCs was higher in chitosan channels when compared to direct injection. In contrast to the first study, the injured site was not completely bridged, possibly due to less effective cell attachment and adherence to the uncoated chitosan channel [222].

Johnson et al. [223] evaluated the feasibility of using fibrin scaffolds to treat SCI and found that the implanted scaffolds enhanced the outgrowth of neural fibers and boosted the migration of cells into the wounded site. After injury, inhibitory molecules from astroglial scars formed at the injury site can prohibit axonal regeneration. In this study, the use of a fibrin scaffold impeded the accumulation of astrocytes at the injury site, which could potentially enhance the regeneration process. In order to overcome the poor cell survival and uncontrolled differentiation of embryonic stem cell-derived neuronal progenitor cell (ESNPC) post-transplantation when treating SCI, Johnson et al. [224] embedded ESNPC in fibrin scaffolds containing neurotrophin-3 (NT-3) and platelet-derived growth factor (PDGF), or NT-3, PDGF and heparin-binding delivery system (HBDS). An increase of cell survival and differentiation was observed when transplanting ESNPCs in fibrin scaffolds containing NT-3 and PDGF. As a result, the addition of HBDS increased the number of $\mathrm{NeuN}^{+}$neurons derived from ESNPCs.

Murakami et al. [215] derived NPCs from fetal rat hippocampus, and embedded these cells in an atelocollagen (a water-soluble collagen) gel and investigated their effect on repairing a 15-mm nerve defect in a rat peripheral nerve injury model, and concluded that NPCs' abilities remained in collagen gel and part of the NPCs might have differentiated into Schwann-like supportive cells, which enhanced axonal regeneration [215].

Embryonic stem cells (ESCs), derived from totipotent cells of the embryo, are pluripotent cells that can differentiate into various cell lineages and proliferate actively [225]. Cui et al. [226] evaluated the efficacy of ES-NPCs on enhancing peripheral nerve regeneration. A 10-mm sciatic nerve segment was removed from the epineurium of a rat model; however, the epineurium was left in the body. ES-NPCs were then injected into the epineurium, which served as a natural conduit. Three months after surgery the diameter of regenerated nerve grew close to normal level, and regenerated axons were myelinated 
and linked the proximal stump to the distal stump. The amplitude of evoked action potentials was detected to be near normal value in ES-NPCs group, while little recovery was detected in the control group. Transplanted neutrally induced ESCs survived and differentiated into cells that formed myelin [226].

Since NSCs are not readily accessible, stem cells derived from non-neural tissue, such as skin-derived stem cells (SDSCs), have gained attention. Marchesi et al. [227] transplanted SDSCs into both a poly(L-lactide-co-trimethylene carbonate) conduit and a collagen conduit to repair a 16-mm sciatic nerve defect in a rat model. At 90 days, SDSCs-filled conduits were much superior to control conduits with regard to the sciatic function index (SFI) and conduction velocity. Although a complete tissue cable linking proximal and distal stumps was present in both cell-seeded and -unseeded conduits, the tissue was more stable and consistent in SDSCs-filled conduits. The mean number of myelinated axons was much greater in SDSC-filled conduits than the control ones. The reason for the promoting effect of SDSCs may be that they express neurotrophic factors that enhance peripheral neural regeneration [227].

\subsubsection{Ectomesenchymal Stem Cells (EMSCs)}

EMSCs can differentiate into Schwann cells during embryonic development [213]. Nie et al. [213] investigated the effect of EMSCs on peripheral nerve regeneration by bridging a $10-\mathrm{mm}$ defect in the sciatic nerve of a rat model using a PLGA conduit filled with EMSCs suspended in type I collagen. Four months after surgery, regenerated nerves were observed in all except the control group. The PLGA conduits were almost totally absorbed. The mean SFI was recorded after 3 months of the surgery, and the result showed that autograft was the highest followed by EMSC-seeded PLGA conduit and cell-free PLGA conduit. There was no statistical difference between the autograft group and EMSC-seeded PLGA group with regard to the recovery of nerve function, to both of which the cell-free PLGA group was significantly inferior. The result also revealed that EMSCs survived the transplantation and remained in the transplantation site [213].

\subsubsection{Mesenchymal Stem Cells (MSCs)}

Mesenchymal stem cells, to which marrow stromal cells are often referred, are multipotent cells in adult marrow, which can differentiate into connective tissues such as bone, cartilage, or tendons [228-230]. Hofstetter et al. discovered that MSCs survived better at the injury site when transplanted 1 week after contusive SCI compared to immediate treatment in rats, and subsequently formed a nerve tissue connecting the injury epicenter [231]. Ankeny et al. also made an attempt to repair neural defect by transplanting previously cultured MSCs to a contusive SCI site in rats [232]. The cells survived after at least 2 months, partly filled the cavities without overgrowing them at the injury, and integrated into the host tissue. MSC transplants also provided a supportive scaffold for axonal growth. In addition, the transplants were found to be capable of longitudinally directing the regenerating axons. Furthermore, although MSCs did not improve motor functional recovery, they induced some hindlimb stepping activity, which might be attributable to the release of a diffusible cell-activating substance [232]. In order to assess the effects of BMSC dose, transplantation site and 
time (during and after SCI) on SCI repair, Pal et al. transplanted human BMSCs into a contusive SCI rat model [233]. They found that the cell transplantation significantly improved the motor and sensory functional recovery and larger dose of cells showed better results. The lumbar puncture method was more suitable for cell transplantation. Results from injection of cells during or after the injury were comparative, suggesting that the injection time might not be critical. BMSCs survived for more than 30 days and found to have migrated to the injury site. However, those cells were not observed to have differentiated into other cells, possibly due to the short residing duration of the cells in the lesion site [233]. In contrast to previous findings, Himes et al. discovered, based on a contusion SCI rat model, that the survival of BMSCs consistently declined during the course of study and failed to detect their robust survival 11 weeks after surgery [234]. Nevertheless, the presence of BMSCs, though for merely a short period of time, sufficed modest functional recovery. They also altered the cell injection protocol by injecting cells into not only the epicenter of the injury but also rostral and caudal to the injury site, which showed significant functional improvement [234].

Hejcl et al. evaluated the effects of the transplantation of a MSC-seeded poly N-(2-hydroxypropyl)methacrylamide with an attached oligopeptide sequence (HPMA-RGD) hydrogel on improving functional recovery in chronic SCI (5 weeks after injury) in rats [22]. The group that was treated with a cell-seeded hydrogel showed statistically significant improvement in terms of motor and sensory function recovery 6 months after SCI, compared to much less significant improvement in the control groups. Histologically, secondary tissue loss was impeded in the group treated with MSC-seeded hydrogel, and Schwann-cell myelinated axons, blood vessels and astrocytes were also found to be present in the cell-seeded hydrogel [22].

McKenzie et al. [235] have used skin-derived precursors (SKPs) to produce Schwann cells. The SKPs, when treated with neural crest cues, generated Schwann cells which produced myelin proteins in vivo. These cells were then used in a rodent contusion model of SCI, where the SKP-derived Schwann cells were able to myelinate axons, reduced reactive gliosis, and improved functional recovery [236]. SKP-Schwann cells can be isolated from adult human skin, and are thus an accessible source of autologous cells for treating spinal cord injury.

Pereira Lopes et al. [212] filled a biodegradable collagen tube with bone marrow-derived cells (BMDCs), a subset of MSCs, to bridge a 3-mm sciatic nerve gap in a mouse model. BMDCs were observed to express two neural growth factors, BDNF and NGF $\beta$, the former of which was not expressed by the cultured cells. Six weeks after implantation, many regenerating clusters, which were formed on regenerating nerves, consisted of both myelinated and non-myelinated nerve fibers in the BMDCs-filled tube, compared to the cell-free control group in which only smaller and less recognizable regenerating clusters could be seen. Quantitative analysis revealed that the number of myelinated fibers decreased in the control group. With regard to fiber area, myelin area and axon area, results from BMDC-filled tube were superior to those from the control group. In addition, the motor function recovery was also faster in the cell-seeded tube than the control tube [212]. Figure 6 shows the semi-thin cross-sections of regenerated nerve tissues of both cell-seeded (A and B) and control (C and D) groups. Figure 6(A) shows the regenerated nerve tissue, and Figure 6(B) shows both clusters of newly regenerated nerve fibers (arrows) and blood vessels. Figure 6(C) (control) shows a less organized regenerated nerve tissue with no pronounced clusters of newly regenerated nerve fibers, while only large and empty blood vessels (arrows) can be seen in D [212]. 
Figure 6. Semi-thin cross-sections of regenerated nerve tissues 6 weeks after injury. A and B: bone marrow-derived cell (BMDC)-seeded group; C and D: control group. Scale bar: $40 \mu \mathrm{m}$. Reprinted from [212] with permission from Elsevier.

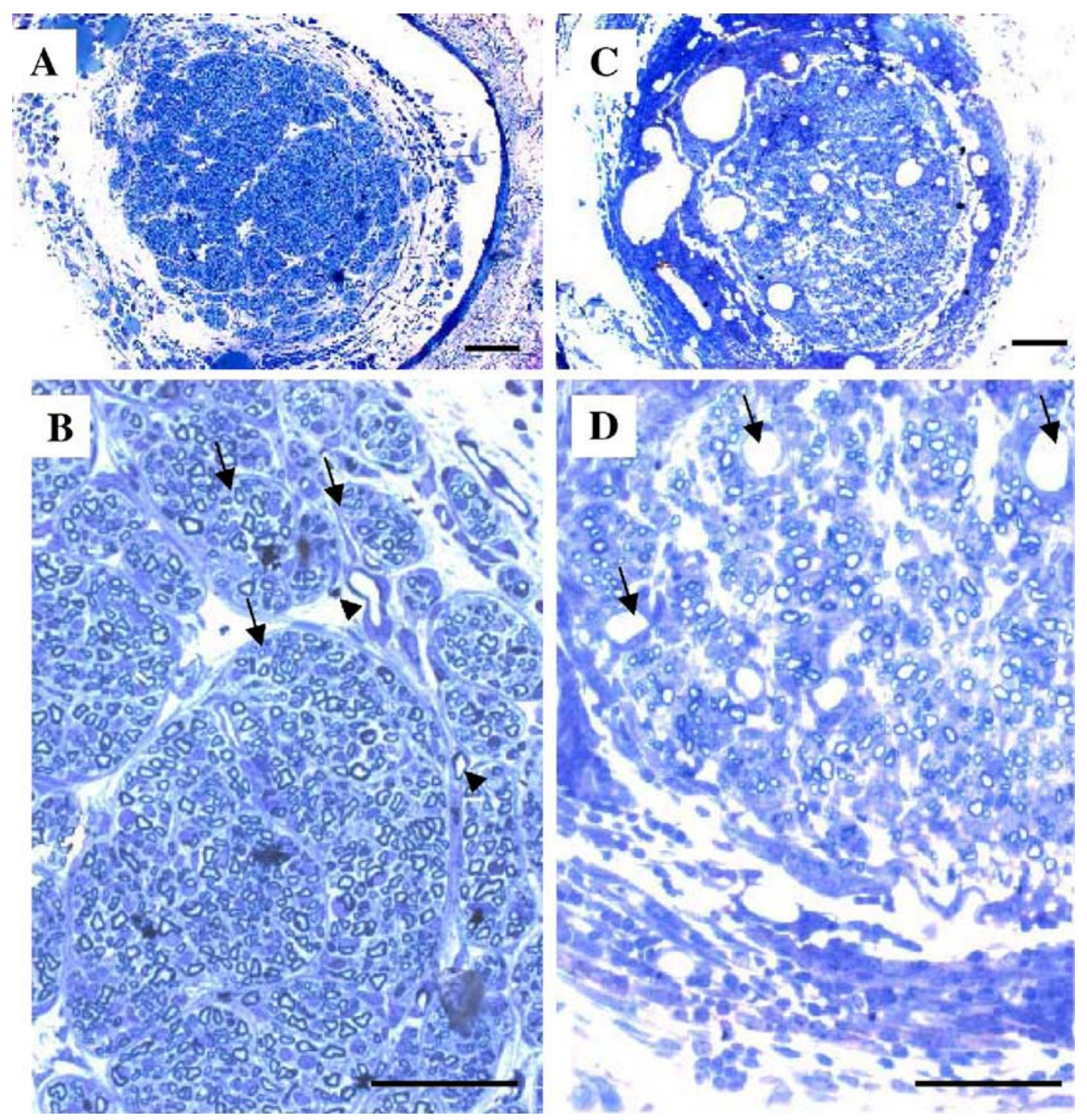

Di Summa et al. [237] compared the effectiveness of Schwann cells, MSCs and adipose-derived stem cells (ADSCs) on enhancing peripheral neural regeneration by seeding each of them into a fibrin conduit to repair a $10-\mathrm{mm}$ sciatic nerve gap in a rat model. When comparing the resulting axonal regeneration distance, conduits seeded with Schwann cells showed the best result, followed by conduits seeded with MSCs and ADSCs and the empty control group. Statistically, results from conduits filled with ADSCs were similar to those from conduits filled with MSCs concerning axonal regeneration distance and Schwann cell invasion (S100). When it comes to clinical application, ADSCs may be advantageous to MSCs due to their greater abundance and less painful isolation process [237]. 


\subsection{Olfactory Ensheathing Cells}

OECs ensheath and direct non-myelinated olfactory axons from the nasal epithelium to the olfactory bulb during development [238,239]. They also facilitate regeneration of olfactory axons. Present in both central and peripheral nervous systems, OECs possess similarities with both Schwann cells and astrocytes [238,239]. OECs have shown promising results when transplanted to treat SCI [240,241], possibly due to the fact that they express NGF and neurotrophic factors [242], and secrete proteins which can indirectly change the activation states of Schwann cell, and thus enhance neurite outgrowth [243]. Li et al. transplanted OECs to the contused spinal cord of a rat model 1 week post injury, and found that OECs survived in the host tissue and migrated to the undamaged cord, albeit in short distance and a small number, in the first 3 weeks after transplantation, but gradually decreased later in both lesion and adjacent sites [244]. A significantly larger intact tissue area and smaller injured tissue area were observed in OECs-treated rat group, indicating that OECs had successfully reduced secondary tissue degeneration. An improved performance of motor and conductive functions was also observed in OECs-treated rat group. However, the transplantation of OECs did not reduce the cavity formation [244]. In a bid to address the questions raised by some researchers [245] regarding the efficacy of OECs in treating SCI, Novikova et al. investigated the influence of culture preparation of OECs on repairing SCI and concluded that the age of OEC in culture and cell purification method could impact their neural repair outcome [246]. Li et al. [238] evaluated OECs in promoting axonal regeneration in peripheral nerve injury by seeding them with ECM gel in both PLGA and silicone using a rat model. Test results from gross observation, relative diameter recovery rates, total fiber number, fiber density and diameter and electrophysiology recovery confirmed that OEC-seeded PLGA conduit outperformed the other groups. This research also revealed the good compatibility between PLGA and OECs. The mechanisms for regeneration-promoting effect of OECs might be: (1) OECs release neurotrophic factors that support axonal recovery and prevent axon and neuron retraction and atrophy; (2) rapid proliferation of OECs across the conduit thwarts the invasion of fibroblasts, which are known to produce scars at the injury site and prevent axons from recovering. Moreover, better electrophysiological results from OEC-seeded PLGA tube than OEC-seeded silicone tube showed that nutrient exchange between the inside and the outside of the conduit also plays a critical role in axonal regeneration [238].

\subsection{Neurotrophic Factors}

Finally, guidance or conduit treatment accompanied with cellular elements may also require the addition of growth factors to facilitate the process of central and peripheral neural regeneration. Vascular endothelial growth factor (VEGF) has been demonstrated to promote neurite outgrowth, possibly due to its role in repressing cell apoptosis pursuant to SCI [247-249]. Widenfalk et al. treated SCI in a rat contused spinal cord model with VEGF, and the results showed that VEGF facilitated behavior improvement, increased spared tissue and blood vessel density, and decreased the levels of apoptosis [250]. Sundberg et al. also undertook a study on the effect of acute administration of VEGF on SCI repair using a rat model, and they too discovered attenuated cavity formation and increased spared tissue induced by VEGF [30]. In addition, VEGF might facilitate enhancing a permissive 
environment for axonal regrowth. However, VEGF might also stimulate plasticity, which might result in chronic pains [30]. On the contrary to the promising results reported by others, Benton et al. discovered that VEGF therapy might exacerbate SCI, possibly due to the growth factor-induced microvascular permeability [251]. Neurothrophin-3 (NT-3), a neurotrophic factor, has been found to enhance central nerve regeneration, particularly the corticospinal tracts [252,253]. Fan et al. combined a PLGA conduit with NT-3 to treat a completely transected SCI using a rat model and observed a beneficial effect of this combination therapy in terms of neural regrowth and locomotor functional recovery [26]. Another neurotrophic factor, acidic fibroblast growth factor (a-FGF), a normal component of the spinal cord, has been demonstrated to promote functional recovery in SCI models, possibly due to its role in impeding or decreasing secondary injury and inducing neuroprotective protein factors [254-257]. Basic fibroblast growth factor (b-FGF), a pleiotropic growth factor, has been found to enhance the proliferation of NSCs and NPCs in healthy adult rat spinal cord [258,259]. However, the research on the effect of b-FGF on promoting axonal regeneration and improving functional recovery in SCI has produced mixed results [260,261]. One of the most extensively studied neurotrophic factors, BDNF, has been employed to treat SCI in a number of injury models [262-265]. In order to overcome the difficulty in retaining BDNF once delivered in the solution form at the injury site due to its fast diffusion to immediate environment, Liang et al. fused BDNF with a collagen-binding domain and used it to repair nerve injury in a crushed rat SCI model [266]. The sustained delivery of BDNF was found to be successful in collagen-binding BDNF when compared with BDNF without bound collagen, and functional recovery and neural regeneration were also enhanced in collagen-binding BDNF treated rat group [266].

Bryan et al. [267] isolated Schwann cells from the sciatic nerve segment in a rat model and seeded them onto PLGA guides, with or without glial growth factor (GGF). Four groups of PLGA guides were then used to bridge a 10-mm nerve gap in rats: (1) conduits seeded with Schwann cells and GGF (SC-GGF); (2) conduits seeded with Schwann cells and saline (SC-S); (3) conduits with GGF (GGF); (4) conduits with and saline (S). At 4 weeks, all groups showed vascularized regenerated nerve tissue, consisting of both myelinated and nonmyelinated axons, across the entire gap. At 12 weeks, the GGF group saw the highest numbers of myelinated, unmyelinated, total axons and blood vessels, while the SC-GGF group had the lowest number of total axons. Although the addition of Schwann cells reduced the total axon count and number of myelinated axons compared to the saline group, the myelination index (MI), the ratio of myelin to axon surface area, of the SC-GGF group was superior to the other three groups. Nerve conduction velocity improved from week 4 to week 12 in all four groups, while the highest was also recorded in the SC-GGF group at 12 weeks [267]. Aebischer et al. [268] studied the supporting effect of b-FGF and/or alpha-1 glycoprotein ( $\alpha 1-\mathrm{GP})$ controllably released from an ethylene-vinyl acetate (EVA) guide on repairing a 15-mm nerve gap in a rat model. An impermeable polymer coat was deposited on the guide prior to implantation, which guided the proteins to release inwardly to the lumen. The mechanism for regeneration-promoting effect of b-FGF might be that it directly reacted with neural element or it indirectly enhanced the proliferation of Schwann cells $[268,269]$. It was also suggested that the supporting role of $\alpha 1-\mathrm{GP}$ in regeneration might be due to its involvement in preventing b-FGF from losing its activeness [268]. Cordeiro et al. [270] examined the effect of a-FGF on enhancing peripheral neural regeneration by filling a PE guide with it plus collagen-containing heparin and using the guide to bridge a 5-mm sciatic nerve defect in a rat model. 
Tubes filled with collagen and collagen plus heparin were used as controls. Four weeks after surgery, regenerated nerve tissue was present in all three groups. However, the number of myelinated axons at midguide level in a-FGF-contained guides was significantly higher than the other two guides. The quantitative retrograde labeling test revealed that the numbers of horseradish peroxidase-labeled primary neurons, sensory neurons and motor neurons in a-FGF filled guides were greater than those in collagen plus heparin guides, which suggested that the effect of a-FGF on promoting neural regeneration was not merely due to the increase in axonal branching [270].

Hontanilla et al. [271] reported an enhancing effect of BDNF administered with an osmotic pump at the proximal stump on peripheral nerve regeneration. However, the improvement of regeneration induced by retrogradely transported BDNF could not be achieved when BDNF was directly introduced into the cell body [272].

In a brief summary, Schwann cells have been demonstrated to be beneficial in both SCI and PNS injury treatment. Different types (syngeneic, isogeneic and autologous) of Schwann cells, cell density and delivery method (on a scaffold or direct transplantation) may influence the outcome. However, the restricted availability of Schwann cells, due to insufficient donor material and to the laborious culture and expansion process, may limit their use in treating nerve injury. NSCs have also been widely studied for their efficacy in improving functional recovery after nerve injury and the results are generally positive. Dosage and delivery method have been shown to affect the results. In addition, OECs, due to the fact that they are able to secrete proteins and express NGF and neurotrophic factors, have been found successful in enhancing neural regeneration. The age of OECs and cell purification methods have been discovered to impact the treatment result for nerve injury. Furthermore, the investigation of neurotrophic factors, such as VEGF, a-FGF and b-FGF, on repairing nerve injury has also been performed and produced mixed results.

\section{Electrospun Polymer Fiber Scaffolds for Neural Repair}

\subsection{Aligned Electrospun Polymer Fiber Scaffolds Guide Cells}

Although nerve guides made from other materials, such as hydrogels, via other fabrication technologies, such as phase separation, have shown promising results, those made from electrospun polymer fibers have great potential in advancing the guidance conduit technology for nerve repair. The fibers can incorporate supportive cells and/or neurotrophic factors for neural regeneration in a simple process In addition, as discussed in Section 2.3, highly aligned fibers can be readily produced via the electrospinning process. Aligned fibers can offer a directional and stimulatory cue for neurite outgrowth, even in the absence of other chemical cues. As mentioned in Section 4, Schwann cells and stem cells can enhance the neural regeneration process. Although the differentiation and proliferation of these cells can be influenced by available biochemical signals, the physical pattern of the basement membrane ECM also has a large impact [273]. Scaffolds consisting of electrospun fibers mimic the ECM and have been in recent years used to enhance nerve regeneration both in vitro and in vivo. For example, Koh et al. coupled electrospun PLA fibers with laminin and found the protein-modified fibers promoted axonal outgrowth in vitro [274]. Ahmed et al. also found that an electrospun polyamide fibrous scaffold covalently modified with a peptide, tenascin-C, promoted neuronal 
attachment and growth in vitro [275]. However, the same group conducted a subsequent in vivo test of using this peptide-modified electrospun polyamide fibrous scaffold to repair an over hemisected SCI in a rat model [36]. Although peptide-modified nanofibers showed a modest result, but better than untreated nanofibers, in axonal regeneration, the authors concluded that the lack of direction on the fiber implant seemed to hinder the axonal outgrowth [36]. Indeed, as described above in Section 4.1, aligned electrospun fibers have been demonstrated to provide guidance cues to cultured cells, such as Schwann cells, which in turn promote neural regeneration. For instance, when DRGs are cultured on aligned Schwann cells, the speed and amount of neurite elongation is increased [276].

Hurtado et al. compared the efficacy of using conduits consisting of aligned and random electrospun PLA microfibers, respectively, in repairing a completely transected spinal cord with a 3-mm defect in a rat model [277]. The spinal cord gap was filled up with cell populations 4 weeks after surgery in both electrospun fiber conduits, however the group treated with aligned fiber conduit obtained regenerating axons with a much longer length coupled with astrocytes. Although the aligned fiber conduit was destitute of neurtie growth promoters and supportive cells, it was demonstrated to possess the ability of enhancing central nerve regeneration [277]. This phenomenon has been observed by numerous independent research groups. Chow et al. studied the growing behavior of DRG neurons and astrocytes on either aligned or random electrospun polydioxanone (PDS) fiber matrix in vitro [278]. Neither DRG neurons nor astrocytes which grew on random fiber matrix showed directional preference, whereas both DRG neurons and astrocytes which were cultured on aligned fiber matrix grew in the direction that mimicked the one of the underlying matrix and extended longer than those cultured on random fiber matrix. In addition, DRG neurons which were cultured on astrocyte-seeded aligned fiber matrix outgrew and outpaced the ones cultured on astrocyte-free matrix [278]. Kim et al. carried out both in vitro and in vivo studies on the impacts of aligned electrospun poly(acrylonitrile-co-methylacrylate) fibers on neuron outgrowth and Schwann cell migration and repairing a 17-mm nerve gap in a rat peripheral nerve injury model [279]. The result from the in vitro study demonstrated that neurite outgrowth and Schwann cell migration were in the same direction as the aligned fibers and extended significantly longer than those cultured on random fibers. The peripheral nerve regeneration was also significantly improved by the aligned fiber construct. Myelinated axons, coupled with migrated Schwann cells and encompassed by laminin deposition, regenerated throughout the construct, connecting the stumps. In addition, the aligned electrospun fiber construct improved both sensory and motor functions [279]. Schnell et al. [280] investigated the effects of aligned electrospun PCL and collagen/PCL (25:75) nanofibers on enhancing glial cell growth in vitro, guiding cell migration and promoting axonal regeneration. Although results from bioassays revealed that both PCL and collagen/PCL nanofibers showed a positive impact on guiding neurite growth and glial cell migration from DRG explants, collagen/PCL nanofibers significantly outperformed PCL nanofibers. Also, individual sensory neuron analysis confirmed that axonal regeneration on collagen/PCL nanofibers outpaced that on PCL nanofibers. However, the length of neurites on collagen/PCL nanofibers was shorter than that on PCL nanofibers, possibly due to the impeding effect exerted by faster moving glia cells on collagen/PCL nanofibers and the promoting effect due to stronger fasciculation of axons on PCL nanofibers. In addition, collagen/PCL nanofibers improved the adherence of Schwann cells and OECs and the proliferation of fibroblasts when compared to PCL nanofibers. The oriented polymer nanofibers indirectly guided the neurite 
outgrowth through Schwann cells, since there was a tendency that neurites grew on top of Schwann cells while Schwann cells closely contacted the nanofibrous substrate [280].

Improved neural regeneration requires optimization of the electrospinning processing parameters. For example, defective regions on the scaffold should be eliminated. Wang et al. discovered that crossed fibers in the aligned fiber scaffold could be detrimental in axonal outgrowth, and that cell attachment and growth could depend on fiber density [95]. In addition, the diameter of electrospun fibers could also influence cell attachment, proliferation and migration [281]. The electrospinning process can be readily used to produce polymer fibers on the nanometer scale. Scaffolds consisting of nanofibers imitate the ECM more closely, and therefore better promote sub-cellular interactions. Yang et al. examined the response of NSCs when cultured in vitro on a random electrospun PLA nanofibrous scaffold with fiber diameter ranging from 150 to $350 \mathrm{~nm}$ [282]. The results showed that the scaffold enhanced cell adhesion and facilitated cell differentiation and neuron outgrowth [282]. The same group went on to compare the effect of aligned electrospun PLA fibers with fiber diameter on either nano- or micro-scale with that of random fibers on NSCs in vitro [283]. They found that the direction of NSC growth was in line with that of aligned fibers, which was independent of fiber diameter. However, the differentiation rate of NSCs was faster on nanofibers than on microfibers, which was independent of fiber alignment [283].

It is also possible to fabricate a multi-layered structure via electrospinning process for improved mechanical strength. Zhu et al. fabricated an electrospun PLA-PLGA fiber scaffold consisting of two layers: aligned fiber inner layer and random fiber outer layer, and incorporated rolipram, a drug that promotes spinal cord tissue regeneration, into the inner layer of the scaffold [284]. A rat hemisected SCI model was used to test the efficacy of the double-layered scaffold for drug delivery. It was observed that rolipram enhanced the axonal regeneration process and improved the locomotor function recovery compared with the control group. Although the functional recovery in the scaffold alone control group was less successful, it was suggested that aligned nanofibers were imperative in functional recovery, without which axons might not be able to reach the target area [284].

In addition to providing directional cues for cells, aligned fibers may also influence the cell maturation process. Chew et al. [285] evaluated the functional changes in human Schwann cells (hSCs) pertaining to the guidance cues brought by aligned electrospun PCL fibers. The hSCs were cultured on two-dimensional PCL films, or on scaffolds consisting of either randomly oriented or aligned electrospun PCL fibers. The morphology of hSCs cultured on a smooth PCL film was much more spread-out than those cultured on electrospun fibers, both randomly oriented and aligned. Compared to scaffolds consisting of randomly oriented electrospun fibers, on which hSCs appeared to adopt a random orientation, aligned fibrous scaffolds rendered hSCs an aligned and uni-directionally elongated orientation along the fiber axes. The real-time PCR analysis revealed a decrease in expression of neurotrophin and neurotrophic receptors from hSCs cultured on electrospun fibrous scaffolds compared to those cultured on film. This phenomenon indicated that the cells cultured on electrospun fibrous scaffolds were induced into a more mature phenotype, which was corroborated by subsequent gene expression analysis. Furthermore, the up-regulation of P0, a major myelin protein gene, was much more significant in hSCs cultured on aligned scaffolds than randomly oriented ones, indicating a more prominent role of aligned fibers in enhancing maturation of Schwann cells than randomly oriented fibers [285]. 
A combination of cues may further improve the neural regeneration process. Xie et al. [286] investigated the effect of topographic cues and electrical stimulation on axonal regeneration in vitro by using conductive DRG-seeded PCL-polypyrrole (PPy) and PLA-PPy core-sheath nanofibers. Figure 7 shows SEM images of PCL nanofibers and PPy hollow nanotubes (PCL-PPy core-sheath nanofibers were first soaked in DCM to remove PCL in order to obtain PPy hollow nanotubes) and TEM images of PPy hollow nanotubes. In the case of DRG seeding on random PCL-PPy nanofibers, neurites extended outward in all directions, as shown in Figure 8(A). In contrast, in the case of DRG cultured on aligned nanotubes, the aligned nanofibers were able to direct neurite extension parallel to the nanofiber orientation, as shown in Figure 8(C). This result indicated that the presence of PPy coating did not significantly affect the topographic cue exerted by aligned nanofibers on neurite outgrowth. The maximum length of outgrown neurites on aligned scaffolds was much longer than that on random scaffolds, which suggested the aligned fibers also improved the neurite outgrowth rate in addition to directing the extension. A direct current of $250 \mu \mathrm{A}$ was applied to the scaffolds for $4 \mathrm{~h}$ every day to determine the effect of electrical stimulation on DRG extension. On both random and aligned scaffolds, the maximum length of the neurites increased with the presence of electrical stimulation. A more pronounced effect of electrical stimulation on increasing the maximum length of neurites was observed on random scaffolds than aligned scaffolds, which might be due to the limited growth of neurites in a given time. The eccentricity of neurite fields was about the same with or without electrical stimulation as expected.

Figure 7. (A) SEM image of PCL nanofibers; (B) SEM image of PCL hollow nanotubes; (C) and (D) TEM images of PCL hollow nanotubes. Reprinted from [286] with permission from John Wiley and Sons.
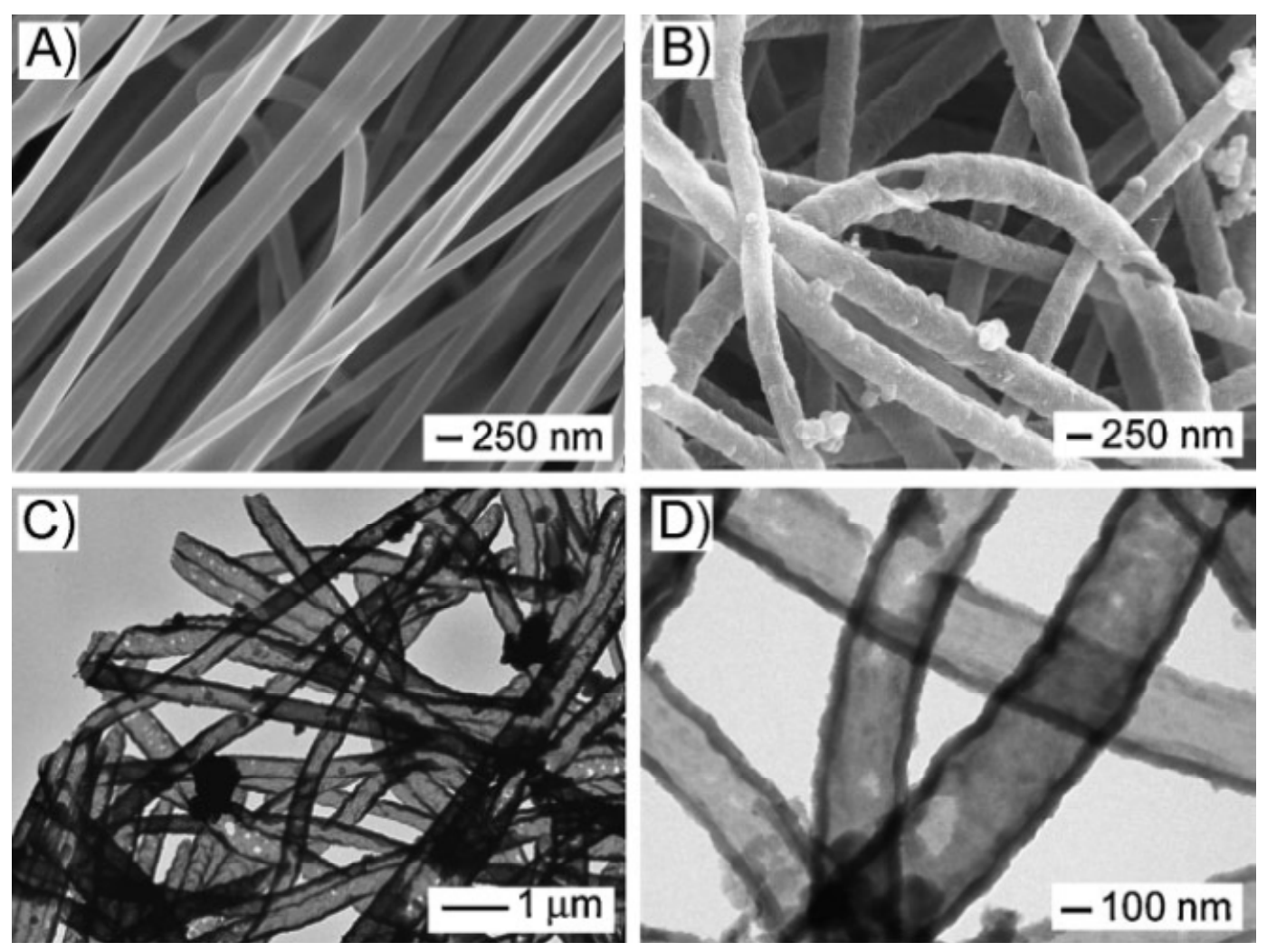
Figure 8. (A) Fluorescence image of DRG neurite field on random PCL-PPy core-sheath nanofibers; (B) SEM Image of aligned PCL-PPy core-sheath nanofibers; (C) Fluorescence image of DRG neurite field on aligned PCL-PPy core-sheath nanofibers. Reprinted from [286] with permission from John Wiley and Sons.
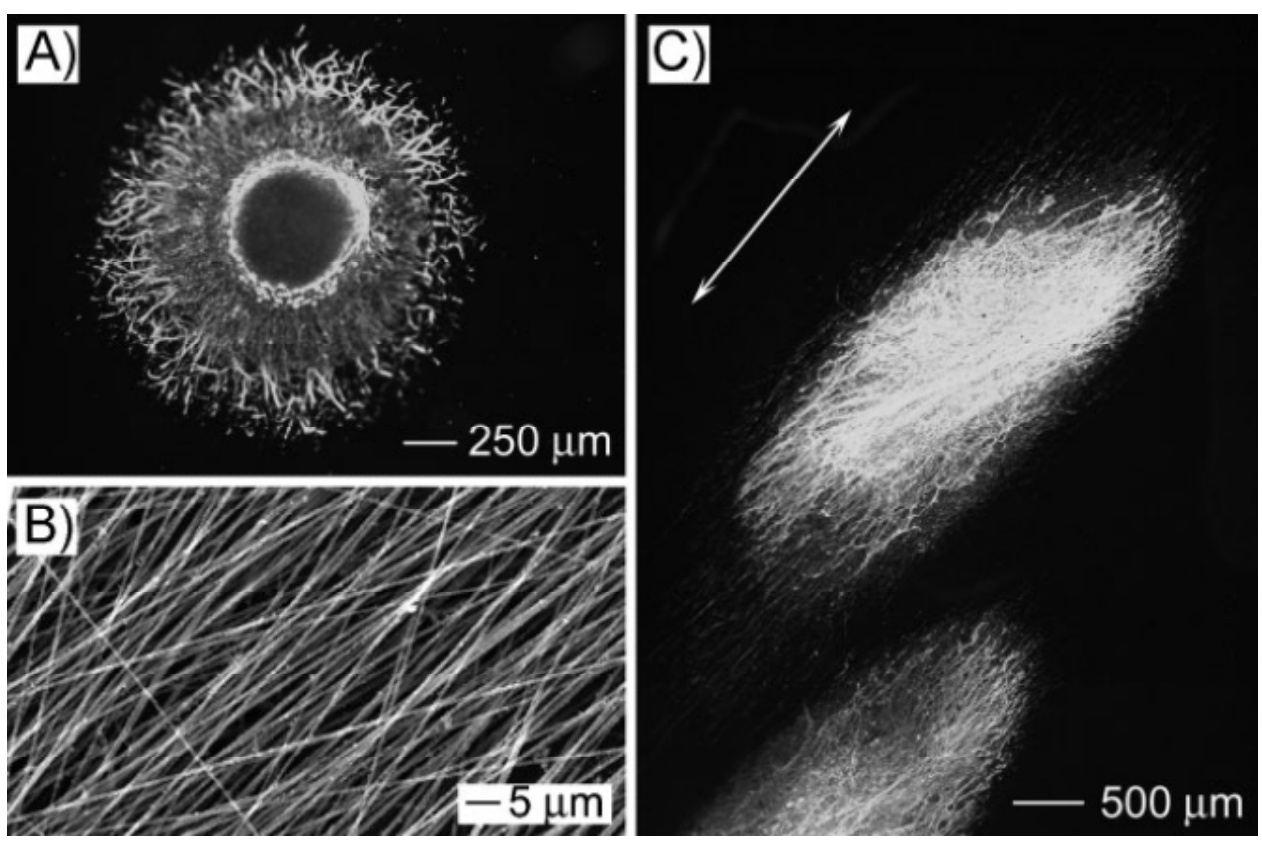

Finally, Townsend-Nicholson and Jayasinghe [287,288] have used electrospinning to produce microthreads of polydimethylsiloxane medium encapsulating living cells. In future, electrospinning of living cell suspensions may be one way to directly seed microfiber structures with living cells.

\subsection{Aligned Schwann Cells Direct Aligned Neurite Outgrowth}

In the absence of other guidance cues, a substrate consisting of aligned Schwann cells will direct overlying neurite extension in an aligned manner.

In order to assess the guiding role played by oriented Schwann cells in neurite outgrowth, Thompson et al. [289] developed a system consisting of a micropatterned substrate with laminin/bovine serum albumin stripes to form aligned Schwann cell monolayers. This system eliminated other possible guidance cues, either chemical or topological, which might also contribute to directing neurite growth, and thus ensured that the only directional cue was provided by the oriented Schwann cells [289]. In their subsequent work, Thompson et al. [203] assessed the in vitro ability of such aligned Schwann cell monolayers to enhance neurite outgrowth. The orientation of dissociated rat spinal neurons which were seeded onto the cell monolayers corresponded to that of the aligned Schwann cells. They attributed this to the cellular topographic cues as well as the molecular cues provided by the Schwann cells [289]. Wang et al. also examined the efficacy of using a Schwann cell seeded aligned electrospun chitosan fibrous tube to repair a $10-\mathrm{mm}$ sciatic nerve defect in a rat model [290]. The in vitro study confirmed the alignment of Schwann cells on the aligned electrospun fibers. Therefore, the cell-seeded aligned fibrous mat could exhibit a Schwann cell column. They subsequently carried out an in vivo study by repairing a sciatic nerve defect in a rat model. Sensory and 
motor functional recovery together with electrophysiological recovery was observed. They also compared the single layer aligned nanofiber tube with a bi-layer tube (aligned nanofiber inner layer and random fiber outer layer) and concluded that the outer layer of the tube was not necessary to provide mechanical strength [290]. Figure 9 shows Schwann cells cultured on both random and oriented electrospun chitosan nanofiber coverslips.

Figure 9. Schwann cell line cultured for 4 days on both random and oriented electrospun chitosan nanofiber coverslips. The row shows Schwann cells cultured on random fibers, while the bottom row shows Schwann cells cultured on oriented fibers. Reprinted from [290] with permission from John Wiley and Sons.
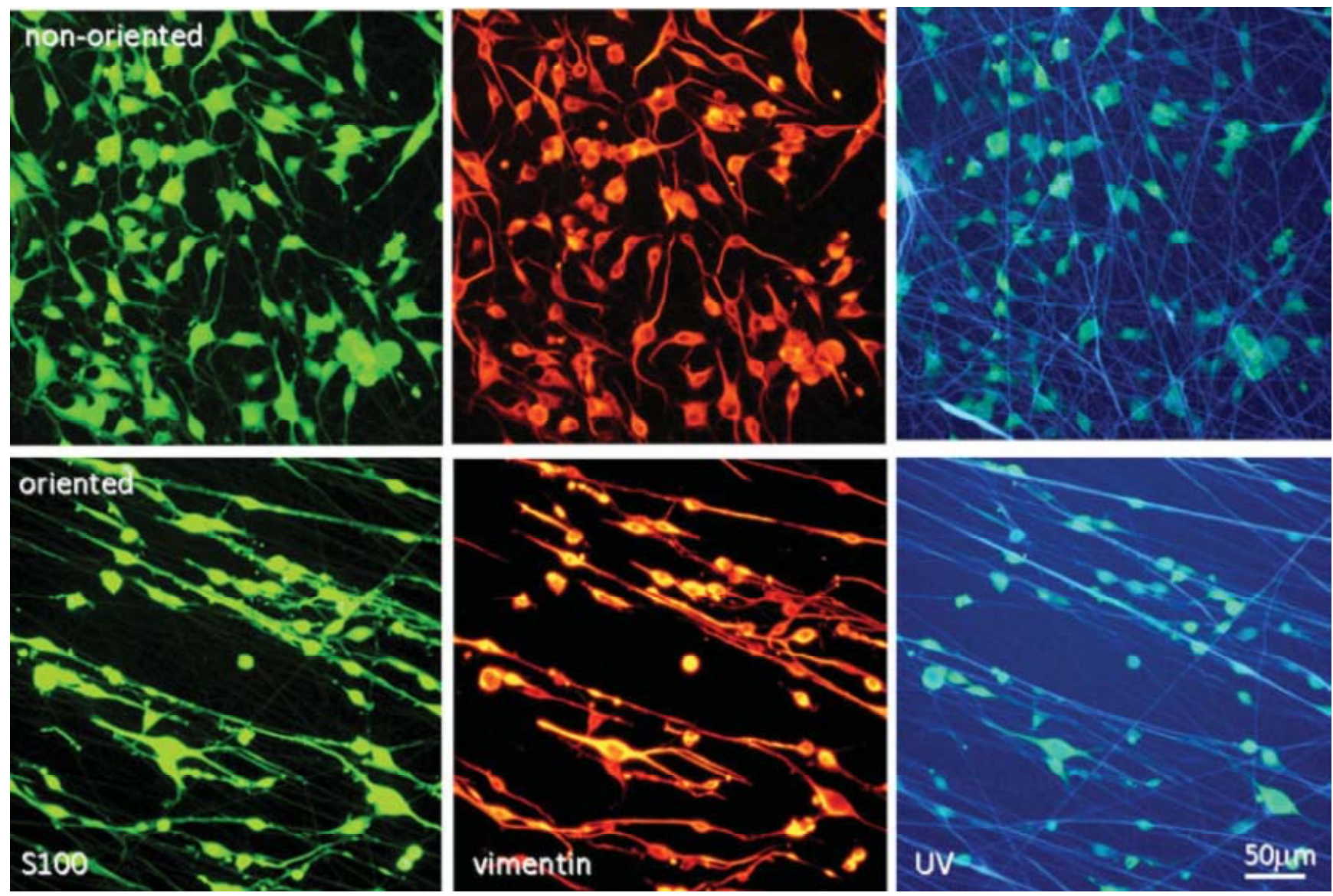

\section{Conclusions}

Intense efforts in developing therapies for peripheral nerve and now spinal cord injury have led to several biologic and pharmacologic treatments which are in pre-clinical investigation. Cellular transplantation has also been investigated. A combination strategy, which involves a cell-seeded engineered scaffold which can support and guide axon regeneration and remyelination may be promising. Electrospinning has been widely used to produce nanofibrous scaffolds which mimic the structure of the natural extracellular matrix. Several electrospinning configurations have been developed to produce mats of aligned fibers. The alignment of the fibers is important for achieving directed cell growth. Ultimately, applications using these structures for neural repair may require that the nanofiber scaffolds eventually biodegrade, leaving behind the regenerated tissue. Biodegradable 
polymers such as PLGA and PCL have already been electrospun into nanofibers, and nerve guidance conduits have been fabricated using these materials. The nanofiber scaffolds can be seeded with cells such as Schwann cells to support and remyelinate the regenerating axons, as well as help them exit the conduit and integrate with the spinal cord.

Prior to translation to clinical trials, any proposed therapy requires evidence of efficacy. These nanofiber structures will need to be tested in animal models to demonstrate their effectiveness. As described in this paper, most of the work to date has involved rodent models. However, evidence of efficacy in large animal models will need to be shown in addition to work in rodent models prior to clinical trials in patients. This will be required especially for therapies involving cell transplantation. Work should also include different injury models, including contusion, compression, and incomplete or full transection. Finally, evidence of behavioral recovery, such as locomotor or other functional recovery, will be required in addition to demonstration of histologic or biochemical recovery.

\section{Acknowledgements}

This work was supported in part by the Natural Sciences and Engineering Research Council of Canada (NSERC).

\section{References}

1. Heath, C.A.; Rutkowski, G.E. The development of bioartificial nerve grafts for peripheral-nerve regeneration. Trends Biotech. 1998, 16, 163-168.

2. National Spinal Cord Injury Statistical Center (NSCISC). Available online: https://www.nscisc.uab.edu/ (accessed on 6 October 2011).

3. Kwon, B.K.; Okon, E.; Hillyer, J.; Mann, C.; Baptiste, D.; Weaver, L.C.; Fehlings, M.G.; Tetzlaff, W. A systematic review of non-invasive pharmacologic neuroprotective treatments for acute spinal cord injury. J. Neurotrauma 2010, 28, 1545-1588.

4. Kwon, B.K.; Okon, E.; Plunet, W.; Baptiste, D.; Fouad, K.; Hillyer, J.; Weaver, L.C.; Fehlings, M.G.; Tetzlaff, W. A systematic review of directly applied biologic therapies for acute spinal cord injury. J. Neurotrauma 2010, 28, 1589-1610.

5. Syková, E.; Homola, A.; Mazanec, R.; Lachmann, H.; Langkramer Konrádová, Š.; Kobylka, P.; Pádr, R.; Neuwirth, J.; Komrska, V.; Vávra, V.; Štulík, J.; Bojar, M. Autologous bone marrow transplantation in patients with subacute and chronic spinal cord injury. Cell Transplant. 2006, $15,675-687$.

6. Geron, C. World's first clinical trial of human embryonic stem cell therapy cleared. Regen. Med. 2009, 4, 161.

7. Guest, J.D.; Rao, A.; Olson, L.; Bunge, M.B.; Bunge, R.P. The ability of human Schwann cell grafts to promote regeneration in the transected nude rat spinal cord. Exp. Neurol. 1997, 148, 502-522.

8. Parr, A.M.; Kulbatski, I.; Zahir, T.; Wang, X.; Yue, C.; Keating, A.; Tator, C.H. Transplanted adult spinal cord-derived neural stem/progenitor cells promote early functional recovery after rat spinal cord injury. Neuroscience 2008, 155, 760-770. 
9. Fitch, M.T.; Doller, C.; Combs, C.K.; Landreth, G.E.; Silver, J. Cellular and molecular mechanisms of glial scarring and progressive cavitation: In vivo and in vitro analysis of inflammation-induced secondary injury after CNS trauma. J. Neurosci. 1999, 19, 8182-8198.

10. Cai, D.; Qiu, J.; Cao, Z.X.; McAtee, M.; Bregman, B.S.; Filbin, M.T. Neuronal cyclic AMP controls the developmental loss in ability of axons to regenerate. J. Neurosci. 2001, 21, 4731-4739.

11. Schwartz, M. Autoimmune Involvement in CNS Trauma is Beneficial if Well Controlled. In Neural Plasticity and Regeneration; Seil, F.J., Ed.; Elsevier Science: Oxford, UK, 2000; Volume 128, pp. 259-263.

12. Widenfalk, J.; Lundstromer, K.; Jubran, M.; Brene, S.; Olson, L. Neurotrophic factors and receptors in the immature and adult spinal cord after mechanical injury or kainic acid. J. Neurosci. 2001, 21, 3457-3475.

13. Ito, T.; Oyanagi, K.; Wakabayashi, K.; Ikuta, F. Traumatic spinal cord injury: A neuropathological study on the longitudinal spreading of the lesions. Acta Neuropathol. 1997, 93, 13-18.

14. Bresnahan, J.C.; Beattie, M.S.; Stokes, B.T.; Conway, K.M. Three-dimensional computer-assisted analysis of graded contusion lesions in the spinal cord of the rat. J. Neurotrauma 1991, 8 , 91-101.

15. Noble, L.J.; Wrathall, J.R. Spinal cord contusion in the rat: Morphometric analyses of alterations in the spinal cord. Exp. Neurol. 1985, 88, 135-149.

16. Skaper, S.D. Neuronal growth-promoting and inhibitory cues in neuroprotection and a neuroregeneration. Ann. N. Y. Acad. Sci. 2005, 1053, 376-385.

17. Friedman, J.A.; Windebank, A.J.; Moore, M.J.; Spinner, R.J.; Currier, B.L.; Yaszemski, M.J. Biodegradable polymer grafts for surgical repair of the injured spinal cord. Neurosurgery 2002, 51, 742-751.

18. Woerly, S.; Pinet, E.; De Robertis, L.; Bousmina, M.; Laroche, G.; Roitback, T.; Vargova, L.; Sykova, E. Heterogeneous PHPMA hydrogels for tissue repair and axonal regeneration in the injured spinal cord. J. Biomater. Sci. Polym. Ed. 1998, 9, 681-711.

19. Syková, E.; Jendelová, P.; Urdzíková, L.; Lesný, P.; Hejčl, A. Bone marrow stem cells and polymer hydrogels - two strategies for spinal cord injury repair. Cell. Mol. Neurobiol. 2006, 26, 1111-1127.

20. Richardson, P.M.; McGuinness, U.M.; Aguayo, A.J. Axons from CNS neurons regenerate into PNS grafts. Nature 1980, 284, 264-265.

21. Doolabh, V.B.; Hertl, M.C.; Mackinnon, S.E. The role of conduits in nerve repair: A review. Rev. Neurosci. 1996, 7, 47-84.

22. Hejcl, A.; Sedy, J.; Kapcalova, M.; Toro, D.A.; Amemori, T.; Lesny, P.; Likavcanova-Masinova, K.; Krumbholcova, E.; Pradny, M.; Michalek, J.; Burian, M.; Hajek, M.; Jendelova, P.; Sykova, E. HPMA-RGD hydrogels seeded with mesenchymal stem cells improve functional outcome in chronic spinal cord injury. Stem Cells Dev. 2010, 19, 1535-1546. 
23. Prang, P.; Müller, R.; Eljaouhari, A.; Heckmann, K.; Kunz, W.; Weber, T.; Faber, C.; Vroemen, M.; Bogdahn, U.; Weidner, N. The promotion of oriented axonal regrowth in the injured spinal cord by alginate-based anisotropic capillary hydrogels. Biomaterials 2006, 27, 3560-3569.

24. Aebischer, P.; Guenard, V.; Winn, S.R.; Valentini, R.F.; Galletti, P.M. Blind-ended semipermeable guidance channels support peripheral nerve regeneration in the absence of a distal nerve stump. Brain Res. 1988, 454, 179-187.

25. Aebischer, P.; Guenard, V.; Brace, S. Peripheral nerve regeneration through blind-ended semipermeable guidance channels: Effect of the molecular weight cutoff. J. Neurosci. 1989, 9, 3590-3595.

26. Fan, J.; Zhang, H.; He, J.; Xiao, Z.; Chen, B.; Xiaodan, J.; Dai, J.; Xu, R. Neural regrowth induced by PLGA nerve conduits and neurotrophin-3 in rats with complete spinal cord transection. J. Biomed. Mater. Res. Part B-Appl. Biomater. 2011, 97B, 271-277.

27. Wood, M.D.; Moore, A.M.; Hunter, D.A.; Tuffaha, S.; Borschel, G.H.; Mackinnon, S.E.; Sakiyama-Elbert, S.E. Affinity-based release of glial-derived neurotrophic factor from fibrin matrices enhances sciatic nerve regeneration. Acta Biomater. 2009, 5, 959-968.

28. Kemp, S.W.P.; Walsh, S.K.; Midha, R. Growth factor and stem cell enhanced conduits in peripheral nerve regeneration and repair. Neurol. Res. 2008, 30, 1030-1038.

29. Xing, R.X.; Liu, J.; Jin, H.; Dai, P.; Wang, T.H. Brain-derived neurotrophic factor and neural plasticity in a rat model of spinal cord transection. Neural Regen. Res. 2011, 6, 1017-1022.

30. Sundberg, L.M.; Herrera, J.J.; Narayana, P.A. Effect of vascular endothelial growth factor treatment in experimental traumatic spinal cord injury: In vivo longitudinal assessment. J. Neurotrauma 2011, 28, 565-578.

31. Davies, S.J.A.; Shih, C.-H.; Noble, M.; Mayer-Proschel, M.; Davies, J.E.; Proschel, C. Transplantation of specific human astrocytes promotes functional recovery after spinal cord injury. Plos One 2011, 6, e17328.

32. Du, B.-L.; Xiong, Y.; Zeng, C.-G.; He, L.-M.; Zhang, W.; Quan, D.-P.; Wu, J.-L.; Li, Y.; Zeng, Y.-S. Transplantation of artificial neural construct partly improved spinal tissue repair and functional recovery in rats with spinal cord transection. Brain Res. 2011, 1400, 87-98.

33. Wang, W.; Lin, J.-H.; Tsai, C.-C.; Chuang, H.-C.; Ho, C.-Y.; Yao, C.-H.; Chen, Y.-S. Biodegradable glutaraldehyde-crosslinked casein conduit promotes regeneration after peripheral nerve injury in adult rats. Macromol. Biosci. 2011, 11, 914-926.

34. Kamada, T.; Koda, M.; Dezawa, M.; Anahara, R.; Toyama, Y.; Yoshinaga, K.; Hashimoto, M.; Koshizuka, S.; Nishio, Y.; Mannoji, C.; Okawa, A.; Yamazaki, M. Transplantation of human bone marrow stromal cell-derived Schwann cells reduces cystic cavity and promotes functional recovery after contusion injury of adult rat spinal cord. Neuropathology 2011, 31, 48-58.

35. Panseri, S.; Cunha, C.; Lowery, J.; Del Carro, U.; Taraballi, F.; Amadio, S.; Vescovi, A.; Gelain, F. Electrospun micro- and nanofiber tubes for functional nervous regeneration in sciatic nerve transections. BMC Biotech. 2008, 8, 39-51.

36. Meiners, S.; Ahmed, I.; Ponery, A.S.; Amor, N.; Harris, S.L.; Ayres, V.; Fan, Y.; Chen, Q.; Delgado-Rivera, R.; Babu, A.N. Engineering electrospun nanofibrillar surfaces for spinal cord repair: A discussion. Polym. Int. 2007, 56, 1340-1348. 
37. Fennessey, S.F.; Farris, R.J. Fabrication of aligned and molecularly oriented electrospun polyacrylonitrile nanofibers and the mechanical behavior of their twisted yams. Polymer 2004, $45,4217-4225$.

38. Rho, K.S.; Jeong, L.; Lee, G.; Seo, B.M.; Park, Y.J.; Hong, S.D.; Roh, S.; Cho, J.J.; Park, W.H.; Min, B.M. Electrospinning of collagen nanofibers: Effects on the behavior of normal human keratinocytes and early-stage wound healing. Biomaterials 2006, 27, 1452-1461.

39. Kubinová, Š.; Syková, E. Nanotechnology for treatment of stroke and spinal cord injury. Nanomedicine 2010, 5, 99-108.

40. Hay, E.D. Cell Biology of Extracellular Matrix, 2nd ed.; Plenum Press: New York, NY, USA, 1991.

41. Seidlits, S.K.; Lee, J.Y.; Schmidt, C.E. Nanostructured scaffolds for neural applications. Nanomedicine 2008, 3, 183-199.

42. Li, W.J.; Laurencin, C.T.; Caterson, E.J.; Tuan, R.S.; Ko, F.K. Electrospun nanofibrous structure: A novel scaffold for tissue engineering. J. Biomed. Mater. Res. 2002, 60, 613-621.

43. Chew, S.Y.; Wen, Y.; Dzenis, Y.; Leong, K.W. The role of electrospinning in the emerging field of nanomedicine. Curr. Pharm. Des. 2006, 12, 4751-4770.

44. Vieu, C.; Carcenac, F.; Pepin, A.; Chen, Y.; Mejias, M.; Lebib, A.; Manin-Ferlazzo, L.; Couraud, L.; Launois, H. Electron beam lithography: Resolution limits and applications. Appl. Surface Sci. 2000, 164, 111-117.

45. Andersson, A.S.; Brink, J.; Lidberg, U.; Sutherland, D.S. Influence of systematically varied nanoscale topography on the morphology of epithelial cells. IEEE Trans. Nanobiosci. 2003, 2, 49-57.

46. Rubenstein, D.; Han, D.; Goldgraben, S.; El-Gendi, H.; Gouma, P.-I.; Frame, M.D. Bioassay chamber for angiogenesis with perfused explanted arteries and electrospun scaffolding. Microcirculation 2007, 14, 723-737.

47. Pattison, M.A.; Wurster, S.; Webster, T.J.; Haberstroh, K.M. Three-dimensional, nano-structured PLGA scaffolds for bladder tissue replacement applications. Biomaterials 2005, 26, 2491-2500.

48. Yang, F.; Murugan, R.; Ramakrishna, S.; Wang, X.; Ma, Y.X.; Wang, S. Fabrication of nano-structured porous PLLA scaffold intended for nerve tissue engineering. Biomaterials 2004, 25, 1891-1900.

49. Hartgerink, J.D.; Beniash, E.; Stupp, S.I. Peptide-amphiphile nanofibers: A versatile scaffold for the preparation of self-assembling materials. Proc. Natl. Acad. Sci. USA 2002, 99, 5133-5138.

50. Li, D.; Wang, Y.; Xia, Y. Electrospinning of polymeric and ceramic nanofibers as uniaxially aligned arrays. Nano Lett. 2003, 3, 1167-1171.

51. Ziabicki, A. Fundamentals of Fibre Formation: The Science of Fibre Spinning and Drawing; Wiley: New York, NY, USA, 1976.

52. Dzenis, Y. Spinning continuous fibers for nanotechnology. Science 2004, 304, 1917-1919.

53. Ma, Z.W.; Kotaki, M.; Yong, T.; He, W.; Ramakrishna, S. Surface engineering of electrospun polyethylene terephthalate (PET) nanofibers towards development of a new material for blood vessel engineering. Biomaterials 2005, 26, 2527-2536.

54. Ma, Z.W.; Kotaki, M.; Inai, R.; Ramakrishna, S. Potential of nanofiber matrix as tissue-engineering scaffolds. Tissue Eng. 2005, 11, 101-109. 
55. Huang, Z.-M.; Zhang, Y.Z.; Kotaki, M.; Ramakrishna, S. A review on polymer nanofibers by electrospinning and their applications in nanocomposites. Composites Sci. Technol. 2003, 63, 2223-2253.

56. Subbiah, T.; Bhat, G.S.; Tock, R.W.; Pararneswaran, S.; Ramkumar, S.S. Electrospinning of nanofibers. J. Appl. Polym. Sci. 2005, 96, 557-569.

57. Srivastava, Y.; Marquez, M.; Thorsen, T. Multijet electrospinning of conducting nanofibers from microfluidic manifolds. J. Appl. Polym. Sci. 2007, 106, 3171-3178.

58. Srivastava, Y.; Loscertales, I.; Marquez, M.; Thorsen, T. Electrospinning of hollow and core/sheath nanofibers using a microfluidic manifold. Microfluid. Nanofluid. 2008, 4, 245-250.

59. Bognitzki, M.; Frese, T.; Steinhart, M.; Greiner, A.; Wendorff, J.H.; Schaper, A.; Hellwig, M. Preparation of fibers with nanoscaled morphologies: Electrospinning of polymer blends. Polym. Eng. Sci. 2001, 41, 982-989.

60. Koombhongse, S.; Liu, W.X.; Reneker, D.H. Flat polymer ribbons and other shapes by electrospinning. J. Polym. Sci. Part B-Polym. Phys. 2001, 39, 2598-2606.

61. MacDiarmid, A.G.; Jones, W.E.; Norris, I.D.; Gao, J.; Johnson, A.T.; Pinto, N.J.; Hone, J.; Han, B.; Ko, F.K.; Okuzaki, H.; Llaguno, M. Electrostatically-generated nanofibers of electronic polymers. Synthet. Metal. 2001, 119, 27-30.

62. Reneker, D.H.; Chun, I. Nanometre diameter fibres of polymer, produced by electrospinning. Nanotechnology 1996, 7, 216-223.

63. Taylor, G. Electrically driven jets. Proc. R. Soc. Lond. A 1969, 313, 453-475.

64. Shin, Y.M.; Hohman, M.M.; Brenner, M.P.; Rutledge, G.C. Electrospinning: A whipping fluid jet generates submicron polymer fibers. Appl. Phys. Lett. 2001, 78, 1149-1151.

65. Yarin, A.L.; Koombhongse, S.; Reneker, D.H. Bending instability in electrospinning of nanofibers. J. Appl. Phys. 2001, 89, 3018-3026.

66. Larrondo, L.; Manley, R.S.J. Electrostatic fiber spinning from polymer melts. I. Experimental observations on fiber formation and properties. J. Polym. Sci. Part B-Polym. Phys. 1981, 19, 909-920.

67. Larrondo, L.; Manley, R.S.J. Electrostatic fiber spinning from polymer melts. II. Examination of the flow field in an electrically driven jet. J. Polym. Sci. Part B-Polym. Phys. 1981, 19, 921-932.

68. Larrondo, L.; Manley, R.S.J. Electrostatic fiber spinning from polymer melts. III. Electrostatic deformation of a pendant drop of polymer melt. J. Polym. Sci. Part B-Polym. Phys. 1981, 19, 933-940.

69. Martins, A.; Reis, R.L.; Neves, N.M. Electrospinning: Processing technique for tissue engineering scaffolding. Int. Mater. Mater. Rev. 2008, 53, 257-274.

70. Gupta, P.; Trenor, S.R.; Long, T.E.; Wilkes, G.L. In situ photo-cross-linking of cinnamate functionalized poly(methyl methacrylate-co-2-hydroxyethyl acrylate) fibers during electrospinning. Macromolecules 2004, 37, 9211-9218.

71. Baumgarten, P.K. Electrostatic spinning of acrylic microfibers. J. Colloid Interface Sci. 1971, 36, 71-79.

72. Buchko, C.J.; Chen, L.C.; Shen, Y.; Martin, D.C. Processing and microstructural characterization of porous biocompatible protein polymer thin films. Polymer 1999, 40, 7397-7407. 
73. Casper, C.L.; Stephens, J.S.; Tassi, N.G.; Chase, D.B.; Rabolt, J.F. Controlling surface morphology of electrospun polystyrene fibers: Effect of humidity and molecular weight in the electrospinning process. Macromolecules 2004, 37, 573-578.

74. Deitzel, J.M.; Kleinmeyer, J.; Harris, D.; Tan, N.C.B. The effect of processing variables on the morphology of electrospun nanofibers and textiles. Polymer 2001, 42, 261-272.

75. Doshi, J.; Reneker, D.H. Electrospinning process and applications of electrospun fibers. J. Electrostat. 1995, 35, 151-160.

76. Geng, X.Y.; Kwon, O.H.; Jang, J.H. Electrospinning of chitosan dissolved in concentrated acetic acid solution. Biomaterials 2005, 26, 5427-5432.

77. Jaeger, R.; Bergshoef, M.M.; Batlle, C.M.I.; Schonherr, H.; Vancso, G.J. Electrospinning of ultra-thin polymer fibers. Macromol. Sym. 1998, 127, 141-150.

78. Ki, C.S.; Baek, D.H.; Gang, K.D.; Lee, K.H.; Um, I.C.; Park, Y.H. Characterization of gelatin nanofiber prepared from gelatin-formic acid solution. Polymer 2005, 46, 5094-5102.

79. Lee, J.S.; Choi, K.H.; Do Ghim, H.; Kim, S.S.; Chun, D.H.; Kim, H.Y.; Lyoo, W.S. Role of molecular weight of atactic poly(vinyl alcohol) (PVA) in the structure and properties of PVA nanofabric prepared by electrospinning. J. Appl. Polym. Sci. 2004, 93, 1638-1646.

80. Meechaisue, C.; Dubin, R.; Supaphol, P.; Hoven, V.P.; Kohn, J. Electrospun mat of tyrosine-derived polycarbonate fibers for potential use as tissue scaffolding material. J. Biomater. Sci.-Polym. Ed. 2006, 17, 1039-1056.

81. Mit-uppatham, C.; Nithitanakul, M.; Supaphol, P. Ultratine electrospun polyamide-6 fibers: Effect of solution conditions on morphology and average fiber diameter. Macromol. Chem. Phys. 2004, 205, 2327-2338.

82. Pham, Q.P.; Sharma, U.; Mikos, A.G. Electrospinning of polymeric nanofibers for tissue engineering applications: A review. Tissue Eng. 2006, 12, 1197-1211.

83. Sill, T.J.; von Recum, H.A. Electro spinning: Applications in drug delivery and tissue engineering. Biomaterials 2008, 29, 1989-2006.

84. Sukigara, S.; Gandhi, M.; Ayutsede, J.; Micklus, M.; Ko, F. Regeneration of Bombyx mori silk by electrospinning-Part 1: Processing parameters and geometric properties. Polymer 2003, 44, 5721-5727.

85. Wannatong, L.; Sirivat, A.; Supaphol, P. Effects of solvents on electrospun polymeric fibers: Preliminary study on polystyrene. Polym. Int. 2004, 53, 1851-1859.

86. Yuan, X.Y.; Zhang, Y.Y.; Dong, C.H.; Sheng, J. Morphology of ultrafine polysulfone fibers prepared by electrospinning. Polym. Int. 2004, 53, 1704-1710.

87. Zong, X.H.; Kim, K.; Fang, D.F.; Ran, S.F.; Hsiao, B.S.; Chu, B. Structure and process relationship of electrospun bioabsorbable nanofiber membranes. Polymer 2002, 43, 4403-4412.

88. He, X.; Arsat, R.; Sadek, A.Z.; Wlodarski, W.; Kalantar-zadeh, K.; Li, J. Electrospun PVP fibers and gas sensing properties of $\mathrm{PVP} / 36^{\circ} \mathrm{YX} \mathrm{LiTaO}_{3} \mathrm{SAW}$ device. Sens. Actuat. B: Chem. 2010, 145, 674-679.

89. Formo, E.; Yavuz, M.S.; Lee, E.P.; Lane, L.; Xia, Y. Functionalization of electrospun ceramic nanofibre membranes with noble-metal nanostructures for catalytic applications. J. Mater. Chem. 2009, 19, 3878-3882. 
90. Romo-Uribe, A.; Arizmendi, L.; Romero-Guzman, M.E.; Sepulveda-Guzman, S.; Cruz-Silva, R. Electrospun nylon nanofibers as effective reinforcement to polyaniline membranes. ACS Appl. Mater. Interfaces 2009, 1, 2502-2508.

91. Ignatova, M.; Stoilova, O.; Manolova, N.; Mita, D.G.; Diano, N.; Nicolucci, C.; Rashkov, I. Electrospun microfibrous poly(styrene-alt-maleic anhydride)/poly(styrene-co-maleic anhydride) mats tailored for enzymatic remediation of waters polluted by endocrine disruptors. Eur. Polym. J. 2009, 45, 2494-2504.

92. Corey, J.M.; Lin, D.Y.; Mycek, K.B.; Chen, Q.; Samuel, S.; Feldman, E.L.; Martin, D.C. Aligned electrospun nanofibers specify the direction of dorsal root ganglia neurite growth. J. Biomed. Mater. Res. Part A 2007, 83A, 636-645.

93. Edwards, M.D.; Mitchell, G.R.; Mohan, S.D.; Olley, R.H. Development of orientation during electrospinning of fibres of poly([epsilon]-caprolactone). Eur. Polym. J. 2010, 46, 1175-1183.

94. Moon, S.; Choi, J.; Farris, R.J. Preparation of aligned polyetherimide fiber by electrospinning. J. Appl. Polym. Sci. 2008, 109, 691-694.

95. Wang, H.B.; Mullins, M.E.; Cregg, J.M.; Hurtado, A.; Oudega, M.; Trombley, M.T.; Gilbert, R.J. Creation of highly aligned electrospun poly-L-lactic acid fibers for nerve regeneration applications. J. Neural Eng. 2009, 6, 016001.

96. Theron, A.; Zussman, E.; Yarin, A.L. Electrostatic field-assisted alignment of electrospun nanofibres. Nanotechnology 2001, 12, 384-390.

97. Afifi, A.M.; Nakajima, H.; Yamane, H.; Kimura, Y.; Nakano, S. Fabrication of aligned poly(L-lactide) fibers by electrospinning and drawing. Macromol. Mater. Eng. 2009, 294, 658-665.

98. Huang, Z.M.; Zhang, Y.Z.; Kotaki, M.; Ramakrishna, S. A review on polymer nanofibers by electrospinning and their applications in nanocomposites. Composites Sci. Technol. 2003, 63, 2223-2253.

99. Pan, H.; Li, L.; Hu, L.; Cui, X. Continuous aligned polymer fibers produced by a modified electrospinning method. Polymer 2006, 47, 4901-4904.

100. Yan, H.; Liu, L.; Zhang, Z. Alignment of electrospun nanofibers using dielectric materials. Appl. Phys. Lett. 2009, 95, 143114-143113.

101. Teo, W.E.; Kotaki, M.; Mo, X.M.; Ramakrishna, S. Porous tubular structures with controlled fibre orientation using a modified electrospinning method. Nanotechnology 2005, 16, 918-924.

102. Lee, H.; Yoon, H.; Kim, G. Highly oriented electrospun polycaprolactone micro/nanofibers prepared by a field-controllable electrode and rotating collector. Appl. Phys. A: Mater. Sci. Pro. 2009, 97, 559-565.

103. Badrossamay, M.R.; McIlwee, H.A.; Goss, J.A.; Parker, K.K. Nanofiber assembly by rotary jet-spinning. Nano Lett. 2010, 10, 2257-2261.

104. Kaplan, D.L. Biopolymers from Renewable Resources; Springer: New York, NY, USA, 1998.

105. Almany, L.; Seliktar, D. Biosynthetic hydrogel scaffolds made from fibrinogen and polyethylene glycol for 3D cell cultures. Biomaterials 2005, 26, 2467-2477.

106. Pierschbacher, M.D.; Ruoslahti, E. Cell attachment activity of fibronectin can be duplicated by small synthetic fragments of the molecule. Nature 1984, 309, 30-33. 
107. Hudson, S.M.; Jenkins, D.W. Chitin and Chitosan. In Encyclopedia of Polymer Science and Technology; John Wiley \& Sons, Inc.: Hoboken, NJ, USA, 2002.

108. Li, Z.S.; Ramay, H.R.; Hauch, K.D.; Xiao, D.M.; Zhang, M.Q. Chitosan-alginate hybrid scaffolds for bone tissue engineering. Biomaterials 2005, 26, 3919-3928.

109. Yusof, N.; Wee, A.; Lim, L.Y.; Khor, E. Flexible chitin films as potential wound-dressing materials: Wound model studies. J. Biomed. Mater. Res. Part A 2003, 66A, 224-232.

110. Wang, L.H.; Khor, E.; Wee, A.; Lim, L.Y. Chitosan-alginate PEC membrane as a wound dressing: Assessment of incisional wound healing. J. Biomed. Mater. Res. 2002, 63, 610-618.

111. Schiffman, J.D.; Schauer, C.L. A review: Electrospinning of biopolymer nanofibers and their applications. Polym. Rev. 2008, 48, 317-352.

112. Brown, R.M.J.; Saxena, I.M. Cellulose: Molecular and Structural Biology; Springer: Berlin, Germany, 2007.

113. Cuculo, J.A.; Aminuddin, N.; Frey, M.W. Structure Formation in Polymeric Fibers; Salem, D.R., Ed.; Hanser Gardner Publications, Inc.: Munich, Germany, 2001; pp. 296-328.

114. Kim, C.W.; Frey, M.W.; Marquez, M.; Joo, Y.L. Preparation of submicron-scale, electrospun cellulose fibers via direct dissolution. J. Polym. Sci. Part B-Polym. Phys. 2005, 43, 1673-1683.

115. Kim, C.W.; Kim, D.S.; Kang, S.Y.; Marquez, M.; Joo, Y.L. Structural studies of electrospun cellulose nanofibers. Polymer 2006, 47, 5097-5107.

116. Ma, Z.W.; Kotaki, M.; Ramakrishna, S. Electrospun cellulose nanofiber as affinity membrane. J. Membrane Sci. 2005, 265, 115-123.

117. Son, W.K.; Youk, J.H.; Park, W.H. Preparation of ultrafine oxidized cellulose mats via electrospinning. Biomacromolecules 2004, 5, 197-201.

118. Han, D.; Halada, G.P.; Spalding, B.; Brooks, S.C. Electrospun and oxidized cellulosic materials for environmental remediation of heavy metals in groundwater. ACS Symp. Ser. 2009, 1019, 243-257.

119. Taepaiboon, P.; Rungsardthong, U.; Supaphol, P. Vitamin-loaded electrospun cellulose acetate nanofiber mats as transdermal and dermal therapeutic agents. of vitamin A acid and vitamin E. Eur. J. Pharm. Biopharm. 2007, 67, 387-397.

120. Wu, X.-M.; Branford-White, C.J.; Zhu, L.-M.; Chatterton, N.P.; Yu, D.-G. Ester prodrug-loaded electrospun cellulose acetate fiber mats as transdermal drug delivery systems. J. Mater. Sci. Mater. Med. 2010, 21, 2403-2411.

121. Davis, B.W.; Niamnont, N.; Hare, C.D.; Sukwattanasinitt, M.; Cheng, Q.A. Nanofibers doped with dendritic fluorophores for protein detection. ACS Appl. Mater. Interfaces 2010, 2 , 1798-1803.

122. Chen, L.; Bromberg, L.; Hatton, T.A.; Rutledge, G.C. Electrospun cellulose acetate fibers containing chlorhexidine as a bactericide. Polymer 2008, 49, 1266-1275.

123. Percot, A.; Viton, C.; Domard, A. Optimization of chitin extraction from shrimp shells. Biomacromolecules 2003, 4, 12-18.

124. Noh, H.K.; Lee, S.W.; Kim, J.M.; Oh, J.E.; Kim, K.H.; Chung, C.P.; Choi, S.C.; Park, W.H.; Min, B.M. Electrospinning of chitin nanofibers: Degradation behavior and cellular response to normal human keratinocytes and fibroblasts. Biomaterials 2006, 27, 3934-3944. 
125. Min, B.M.; Lee, S.W.; Lim, J.N.; You, Y.; Lee, T.S.; Kang, P.H.; Park, W.H. Chitin and chitosan nanofibers: Electrospinning of chitin and deacetylation of chitin nanofibers. Polymer 2004, 45, 7137-7142.

126. Homayoni, H.; Ravandi, S.A.H.; Valizadeh, M. Electrospinning of chitosan nanofibers: Processing optimization. Carbohyd. Polym. 2009, 77, 656-661.

127. Ohkawa, K.; Cha, D.I.; Kim, H.; Nishida, A.; Yamamoto, H. Electrospinning of chitosan. Macromol. Rapid Commun. 2004, 25, 1600-1605.

128. Duan, B.; Dong, C.H.; Yuan, X.Y.; Yao, K.D. Electrospinning of chitosan solutions in acetic acid with poly(ethylene oxide). J. Biomater. Sci.-Polym. Ed. 2004, 15, 797-811.

129. Zhang, Y.Y.; Huang, X.B.; Duan, B.; Wu, L.L.; Li, S.; Yuan, X.Y. Preparation of electrospun chitosan/poly(vinyl alcohol) membranes. Colloid Polym. Sci. 2007, 285, 855-863.

130. Lopes-Da-Silva, J.A.; Veleirinho, B.; Delgadillo, I. Preparation and characterization of electrospun mats made of PET/chitosan hybrid nanofibers. J. Nanosci. Nanotechnol. 2009, 9, 3798-3804.

131. Zhang, H.T.; Li, S.B.; White, C.J.B.; Ning, X.; Nie, H.L.; Zhu, L.M. Studies on electrospun nylon-6/chitosan complex nanofiber interactions. Electrochim. Acta 2009, 54, 5739-5745.

132. Chen, F.; Li, X.Q.; Mo, X.M.; He, C.L.; Wang, H.S.; Ikada, Y. Electrospun chitosan-P(LLA-CL) nanofibers for biomimetic extracellular matrix. J. Biomater. Sci.-Polym. Ed. 2008, 19, 677-691.

133. Scheibel, T. Protein fibers as performance proteins: New technologies and applications. Curr. Opin. Biotech. 2005, 16, 427-433.

134. Matthews, J.A.; Wnek, G.E.; Simpson, D.G.; Bowlin, G.L. Electrospinning of collagen nanofibers. Biomacromolecules 2002, 3, 232-238.

135. Sell, S.A.; McClure, M.J.; Garg, K.; Wolfe, P.S.; Bowlin, G.L. Electrospinning of collagen/biopolymers for regenerative medicine and cardiovascular tissue engineering. $A d v$. Drug Delivery Rev. 2009, 61, 1007-1019.

136. Kolacna, L.; Bakesova, J.; Varga, F.; Kostakova, E.; Planka, L.; Necas, A.; Lukas, D.; Amler, E.; Pelouch, V. Biochemical and biophysical aspects of collagen nanostructure in the extracellular matrix. Physiol. Res. 2007, 56, S51-S60.

137. Boland, E.D.; Matthews, J.A.; Pawlowski, K.J.; Simpson, D.G.; Wnek, G.E.; Bowlin, G.L. Electrospinning collagen and elastin: Preliminary vascular tissue engineering. Frontiers Biosci. 2004, 9, 1422-1432.

138. Kidoaki, S.; Kwon, I.K.; Matsuda, T. Mesoscopic spatial designs of nano- and microfiber meshes for tissue-engineering matrix and scaffold based on newly devised multilayering and mixing electrospinning techniques. Biomaterials 2005, 26, 37-46.

139. Li, M.Y.; Mondrinos, M.J.; Gandhi, M.R.; Ko, F.K.; Weiss, A.S.; Lelkes, P.I. Electrospun protein fibers as matrices for tissue engineering. Biomaterials 2005, 26, 5999-6008.

140. Dong, B.; Arnoult, O.; Smith, M.E.; Wnek, G.E. Electrospinning of collagen nanofiber scaffolds from benign solvents. Macromol. Rapid Commun. 2009, 30, 539-542.

141. Zeugolis, D.I.; Khew, S.T.; Yew, E.S.Y.; Ekaputra, A.K.; Tong, Y.W.; Yung, L.-Y.L.; Hutmacher, D.W.; Sheppard, C.; Raghunath, M. Electro-spinning of pure collagen nano-fibresJust an expensive way to make gelatin? Biomaterials 2008, 29, 2293-2305. 
142. Szentivanyi, A.; Assmann, U.; Schuster, R.; Glasmacher, B. Production of biohybrid protein/PEO scaffolds by electrospinning. Materialwiss. Werkstofftech. 2009, 40, 65-72.

143. Choi, J.S.; Lee, S.J.; Christ, G.J.; Atala, A.; Yoo, J.J. The influence of electrospun aligned poly(epsilon-caprolactone)/collagen nanofiber meshes on the formation of self-aligned skeletal muscle myotubes. Biomaterials 2008, 29, 2899-2906.

144. Chen, Z.G.; Mo, X.M.; Qing, F.L. Electrospinning of collagen-chitosan complex. Mater. Lett. 2007, 61, 3490-3494.

145. Chen, R.; Huang, C.; Ke, Q.F.; He, C.L.; Wang, H.S.; Mo, X.M. Preparation and characterization of coaxial electrospun thermoplastic polyurethane/collagen compound nanofibers for tissue engineering applications. Colloid. Surface. B-Biointerface. 2010, 79, 315-325.

146. Boland, E.D.; Coleman, B.D.; Barnes, C.P.; Simpson, D.G.; Wnek, G.E.; Bowlin, G.L. Electrospinning polydioxanone for biomedical applications. Acta Biomater. 2005, 1, 115-123.

147. Wnek, G.E.; Carr, M.E.; Simpson, D.G.; Bowlin, G.L. Electrospinning of nanofiber fibrinogen structures. Nano Lett. 2003, 3, 213-216.

148. Peretti, G.M.; Randolph, M.A.; Zaporojan, V.; Bonassar, L.J.; Xu, J.W.; Fellers, J.C.; Yaremchuk, M.J. A biomechanical analysis of an engineered cell-scaffold implant for cartilage repair. Ann. Plast. Surg. 2001, 46, 533-537.

149. Katti, D.S.; Robinson, K.W.; Ko, F.K.; Laurencin, C.T. Bioresorbable nanofiber-based systems for wound healing and drug delivery: Optimization of fabrication parameters. J. Biomed. Mater. Res. Part B-Appl. Biomater. 2004, 70B, 286-296.

150. McManus, M.C.; Boland, E.D.; Simpson, D.G.; Barnes, C.P.; Bowlin, G.L. Electrospun fibrinogen: Feasibility as a tissue engineering scaffold in a rat cell culture model. J. Biomed. Mater. Res. Part A 2007, 81A, 299-309.

151. You, Y.; Min, B.M.; Lee, S.J.; Lee, T.S.; Park, W.H. In vitro degradation behavior of electrospun polyglycolide, polylactide, and poly(lactide-co-glycolide). J. Appl. Polym. Sci. 2005, 95, 193-200.

152. Li, S.M.; McCarthy, S. Further investigations on the hydrolytic degradation of poly(DL-lactide). Biomaterials 1999, 20, 35-44.

153. Grizzi, I.; Garreau, H.; Li, S.; Vert, M. Hydrolytic degradation of devices based on poly(DL-lactic acid) size-dependence. Biomaterials 1995, 16, 305-311.

154. Hurrell, S.; Cameron, R.E. Polyglycolide: Degradation and drug release. Part I: Changes in morphology during degradation. J. Mater. Sci.-Mater. Med. 2001, 12, 811-816.

155. Zong, X.H.; Ran, S.F.; Kim, K.S.; Fang, D.F.; Hsiao, B.S.; Chu, B. Structure and morphology changes during in vitro degradation of electrospun poly(glycolide-co-lactide) nanofiber membrane. Biomacromolecules 2003, 4, 416-423.

156. Dong, Y.X.; Liao, S.; Ngiam, M.; Chan, C.K.; Ramakrishna, S. Degradation behaviors of electrospun resorbable polyester nanofibers. Tissue Eng. Part B-Rev. 2009, 15, 333-351.

157. Dong, Y.; Yong, T.; Liao, S.; Chan, C.K.; Stevens, M.M.; Ramakrishna, S. Distinctive degradation behaviors of electrospun polyglycolide, poly(DL-lactide-co-glycolide), and poly(L-lactide-co-e-caprolactone) Nanofibers cultured with/without porcine smooth muscle cells. Tissue Eng. Part A 2010, 16, 283-298. 
158. Pan, H.; Jiang, H.L.; Chen, W.L. The biodegradability of electrospun Dextran/PLGA scaffold in a fibroblast/macrophage co-culture. Biomaterials 2008, 29, 1583-1592.

159. Kim, K.; Yu, M.; Zong, X.H.; Chiu, J.; Fang, D.F.; Seo, Y.S.; Hsiao, B.S.; Chu, B.; Hadjiargyrou, M. Control of degradation rate and hydrophilicity in electrospun non-woven poly(D,L-lactide) nanofiber scaffolds for biomedical applications. Biomaterials 2003, 24, 4977-4985.

160. Gilding, D.K.; Reed, A.M. Biodegradable polymers for use in surgery-polyglycolic/poly(actic acid) homo- and copolymers: 1. Polymer 1979, 20, 1459-1464.

161. Jiang, H.L.; Fang, D.F.; Hsiao, B.J.; Chu, B.J.; Chen, W.L. Preparation and characterization of ibuprofen-loaded poly(lactide-co-glycolide)/poly(ethylene glycol)-g-chitosan electrospun membranes. J. Biomater. Sci.-Polym. Ed. 2004, 15, 279-296.

162. Li, W.J.; Cooper, J.A.; Mauck, R.L.; Tuan, R.S. Fabrication and characterization of six electrospun poly(alpha-hydroxy ester)-based fibrous scaffolds for tissue engineering applications. Acta Biomater. 2006, 2, 377-385.

163. Bostman, O.; Hirvensalo, E.; Makinen, J.; Rokkanen, P. Foreign-body reactions to fracture fixation implants of biodegradable synthetic polymers. J. Bone Joint Surg.-Brit. Vol. 1990, 72, 592-596.

164. Ceonzo, K.; Gaynor, A.; Shaffer, L.; Kojima, K.; Vacanti, C.A.; Stahl, G.L. Polyglycolic acid-induced inflammation: Role of hydrolysis and resulting complement activation. Tissue Eng. 2006, 12, 301-308.

165. Agrawal, C.M.; Athanasiou, K.A. Technique to control pH in vicinity of biodegrading PLA-PGA implants. J. Biomed. Mater. Res. 1997, 38, 105-114.

166. Bini, T.B.; Gao, S.J.; Xu, X.Y.; Wang, S.; Ramakrishna, S.; Leong, K.W. Peripheral nerve regeneration by microbraided poly(L-lactide-co-glycolide) biodegradable polymer fibers. J. Biomed. Mater. Res. Part A 2004, 68A, 286-295.

167. Sung, H.J.; Meredith, C.; Johnson, C.; Galis, Z.S. The effect of scaffold degradation rate on three-dimensional cell growth and angiogenesis. Biomaterials 2004, 25, 5735-5742.

168. Hutmacher, D.W.; Schantz, T.; Zein, I.; Ng, K.W.; Teoh, S.H.; Tan, K.C. Mechanical properties and cell cultural response of polycaprolactone scaffolds designed and fabricated via fused deposition modeling. J. Biomed. Mater. Res. 2001, 55, 203-216.

169. Lee, E.-J.; Teng, S.-H.; Jang, T.-S.; Wang, P.; Yook, S.-W.; Kim, H.-E.; Koh, Y.-H. Nanostructured poly(epsilon-caprolactone)-silica xerogel fibrous membrane for guided bone regeneration. Acta Biomater. 2010, 6, 3557-3565.

170. Zuo, Y.; Yang, F.; Wolke, J.G.C.; Li, Y.B.; Jansen, J.A. Incorporation of biodegradable electrospun fibers into calcium phosphate cement for bone regeneration. Acta Biomater. 2010, 6 , 1238-1247.

171. Zamani, M.; Morshed, M.; Varshosaz, J.; Jannesari, M. Controlled release of metronidazole benzoate from poly epsilon-caprolactone electrospun nanofibers for periodontal diseases. Eur. J. Pharm. Biopharm. 2010, 75, 179-185.

172. Yoon, H.; Lee, H.; Park, G.M.; Kim, G. Fabricating highly aligned electrospun poly(epsilon-caprolactone) micro/nanofibers for nerve tissue regeneration. Polym.-Korea 2010, 34, 185-190. 
173. Gupta, D.; Venugopal, J.; Prabhakaran, M.P.; Dev, V.R.G.; Low, S.; Choon, A.T.; Ramakrishna, S. Aligned and random nanofibrous substrate for the in vitro culture of Schwann cells for neural tissue engineering. Acta Biomater. 2009, 5, 2560-2569.

174. Merrell, J.G.; McLaughlin, S.W.; Tie, L.; Laurencin, C.T.; Chen, A.F.; Nair, L.S. Curcumin-loaded poly(epsilon-caprolactone) nanofibres: Diabetic wound dressing with anti-oxidant and anti-inflammatory properties. Clin. Exp. Pharmacol. Physiol. 2009, 36, 1149-1156.

175. Liao, I.C.; Chen, S.L.; Liu, J.B.; Leong, K.W. Sustained viral gene delivery through core-shell fibers. J. Control. Release 2009, 139, 48-55.

176. Pektok, E.; Nottelet, B.; Tille, J.C.; Gurny, R.; Kalangos, A.; Moeller, M.; Walpoth, B.H. Degradation and healing characteristics of small-diameter poly(epsilon-caprolactone) vascular grafts in the rat systemic arterial circulation. Circulation 2008, 118, 2563-2570.

177. Qian, H.T.; Bei, J.Z.; Wang, S.G. Synthesis, characterization and degradation of ABA block copolymer of L-lactide and epsilon-caprolactone. Polym. Degrad. Stabil. 2000, 68, 423-429.

178. Walpoth, B.H.; Cikirikcioglu, M.; Mugnai, D.; Tiller, J.C.; Pektok, E.; Pfister, R.; Palombo, D.; Kalangos, A.; Bowlin, G. Biodegradable small calibre polydioxanone-based vascular prostheses: Potential as coronary bypass grafts. Circulation 2007, 116, 444.

179. Rosen, J.M.; Padilla, J.A.; Nguyen, K.D.; Siedman, J.; Pham, H.N. Artificial nerve graft using glycolide trimethylene carbonate as a nerve conduit filled with collagen compared to sutured autograft in a rat model. J. Rehabil. Res. Develop. 1992, 29, 1-12.

180. Bissell, M.J.; Hall, H.G.; Parry, G. How does the extracellular matrix direct gene expression? J. Theor. Biol. 1982, 99, 31-68.

181. Nakamura, T.; Inada, Y.; Fukuda, S.; Yoshitani, M.; Nakada, A.; Itoi, S.; Kanemaru, S.; Endo, K.; Shimizu, Y. Experimental study on the regeneration of peripheral nerve gaps through a polyglycolic acid-collagen (PGA-collagen) tube. Brain Res. 2004, 1027, 18-29.

182. Okamoto, H.; Hata, K.I.; Kagami, H.; Okada, K.; Ito, Y.; Narita, Y.; Hirata, H.; Sekiya, I.; Otsuka, T.; Ueda, M. Recovery process of sciatic nerve defect with novel bioabsorbable collagen tubes packed with collagen filaments in dogs. J. Biomed. Mater. Res. Part A 2010, 92A, 859-868.

183. Ahmed, M.R.; Venkateshwarlu, U.; Jayakumar, R. Multilayered peptide incorporated collagen tubules for peripheral nerve repair. Biomaterials 2004, 25, 2585-2594.

184. Hammarback, J.A.; Palm, S.L.; Furcht, L.T.; Letourneau, P.C. Guidance of neurite outgrowth by pathways of substratum-adsorbed laminin. J. Neurosci. Res. 1985, 13, 213-220.

185. Manthorpe, M.; Engvall, E.; Ruoslahti, E.; Longo, F.M.; Davis, G.E.; Varon, S. Laminin promotes neuritic regeneration from cultured peripheral and central neurons. J. Cell Biol. 1983, 97, 1882-1890.

186. Rogers, S.L.; Letourneau, P.C.; Palm, S.L.; McCarthy, J.; Furcht, L.T. Neurite extension by peripheral and central nervous system neurons in response to substratum-bound fibronectin and laminin. Develop. Biol. 1983, 98, 212-220.

187. Terranova, V.P.; Rohrbach, D.H.; Martin, G.R. Role of laminin in the attachment of PAM 212 (epithelial) cells to basement membrane collagen. Cell 1980, 22, 719-726.

188. Smalheiser, N.R.; Crain, S.M.; Reid, L.M. Laminin as a substrate for retinal axons in vitro. Develop. Brain Res. 1984, 12, 136-140. 
189. Yoshii, S.; Yamamuro, T.; Ito, S.; Hayashi, M. In vivo guidance of regenerating nerve by laminin-coated filaments. Exp. Neurol. 1987, 96, 469-473.

190. Madison, R.; da Silva, C.F.; Dikkes, P.; Chiu, T.-H.; Sidman, R.L. Increased rate of peripheral nerve regeneration using bioresorbable nerve guides and a laminin-containing gel. Exp. Neurol. 1985, 88, 767-772.

191. Koh, H.S.; Yong, T.; Teo, W.E.; Chan, C.K.; Puhaindran, M.E.; Tan, T.C.; Lim, A.; Lim, B.H.; Ramakrishna, S. In vivo study of novel nanofibrous intra-luminal guidance channels to promote nerve regeneration. J. Neural Eng. 2010, 7, 046003.

192. Wolly, A.L.; Hollowell, J.P.; Rich, K.M. Fibronectin-laminin combination enhances peripheral nerve regeneration across long gaps. Otolaryngol.-Head Neck Surg. 1990, 103, 509-518.

193. Tong, X.-J.; Hirai, K.-I.; Shimada, H.; Mizutani, Y.; Izumi, T.; Toda, N.; Yu, P. Sciatic nerve regeneration navigated by laminin-fibronectin double coated biodegradable collagen grafts in rats. Brain Res. 1994, 663, 155-162.

194. Tetzlaff, W.; Okon, E.B.; Karimi-Abdolrezaee, S.; Hill, C.E.; Sparling, J.S.; Plemel, J.R.; Plunet, W.T.; Tsai, E.C.; Baptiste, D.; Smithson, L.J.; Kawaja, M.D.; Fehlings, M.G.; Kwon, B.K. A systematic review of cellular transplantation therapies for spinal cord injury. J. Neurotrauma 2010, 28, 1611-1682.

195. Oudega, M.; Moon, L.D.F.; de Almeida Leme, R.J. Schwann cells for spinal cord repair. Brazilian J. Med. Biol. Res. 2005, 38, 825-835.

196. Williams, L.R.; Longo, F.M.; Powell, H.C.; Lundborg, G.; Varon, S. Spatial-temporal progress of peripheral nerve regeneration within a silicone chamber: Parameters for a bioassay. J. Comp. Neurol. 1983, 218, 460-470.

197. Bryan, D.J.; Wang, K.K.; ChakalisHaley, D.P. Effect of Schwann cells in the enhancement of peripheral-nerve regeneration. J. Reconstr. Microsurg. 1996, 12, 439-446.

198. Mancardi, G.L.; Cadoni, A.; Tabaton, M.; Schenone, A.; Zicca, A.; Demartini, I.; Bianchini, D.; Damiani, G.; Zaccheo, D. Schwann-cell GFAP expression increases in axonal neuropathies. J. Neurol. Sci. 1991, 102, 177-183.

199. Bunge, R.P. The role of the Schwann cell in trophic support and regeneration. J. Neurol. 1994, 242, S19-S21.

200. Suri, S.; Schmidt, C. Cell-laden hydrogel constructs of hyaluronic acid, collagen, and laminin for neural tissue engineering. Tissue Eng. Part A 2010, 16, 1703-1716.

201. Sorensen, J.; Fugleholm, K.; Moldovan, M.; Schmalbruch, H.; Krarup, G. Axonal elongation through long acellular nerve segments depends on recruitment of phagocytic cells from the near-nerve environment-Electrophysiological and morphological studies in the cat. Brain Res. 2001, 903, 185-197.

202. Keeley, R.; Atagi, T.; Sabelman, E.; Padilla, J.; Kadlcik, P.; Agras, J.; Eng, L.; Wiedman, T.W.; Nguyen, K.; Sudekum, A.; Rosen, J. Synthetic nerve graft containing collagen and synthetic. Schwann cells improves functional, electrophysiological, and histological parameters of peripheral nerve regeneration. Restor. Neurol. Sci. Neurosci. 1993, 5, 353-366.

203. Thompson, D.; Buettner, H. Neurite outgrowth is directed by Schwann cell alignment in the absence of other guidance cues. Ann. Biomed. Eng. 2006, 34, 161-168. 
204. Bunge, R.P.; Bunge, M.B. Interrelationship between Schwann cell function and extracellular matrix production. Trends Neurosci. 1983, 6, 499-505.

205. Xu, X.M.; Zhang, S.X.; Li, H.; Aebischer, P.; Bunge, M.B. Regrowth of axons into the distal spinal cord through a Schwann-cell-seeded mini-channel implanted into hemisected adult rat spinal cord. Eur. J. Neurosci. 1999, 11, 1723-1740.

206. Novikova, L.N.; Pettersson, J.; Brohlin, M.; Wiberg, M.; Novikov, L.N. Biodegradable poly-[beta]-hydroxybutyrate scaffold seeded with Schwann cells to promote spinal cord repair. Biomaterials 2008, 29, 1198-1206.

207. Blits, B.; Oudega, M.; Boer, G.J.; Bartlett Bunge, M.; Verhaagen, J. Adeno-associated viral vector-mediated neurotrophin gene transfer in the injured adult rat spinal cord improves hind-limb function. Neuroscience 2003, 118, 271-281.

208. Guénard, V.; Kleitman, N.; Morrissey, T.K.; Bunge, R.P.; Aebischer, P. Syngeneic Schwann cells derived from adult nerves seeded in semipermeable guidance channels enhance peripheral nerve regeneration. J. Neurosci. 1992, 12, 3310-3320.

209. Rodriguez, F.J.; Verdu, E.; Ceballos, D.; Navarro, X. Nerve guides seeded with autologous Schwann cells improve nerve regeneration. Exp. Neurol. 2000, 161, 571-584.

210. Lohmeyer, J.A.; Shen, Z.L.; Walter, G.F.; Berger, A. Bridging extended nerve defects with an artificial nerve graft containing Schwann cells pre-seeded on polyglactin filaments. Int. J. Artif. Org. 2007, 30, 64-74.

211. Ishikawa, N.; Suzuki, Y.; Dezawa, M.; Kataoka, K.; Ohta, M.; Cho, H.; Ide, C. Peripheral nerve regeneration by transplantation of BMSC-derived Schwann cells as chitosan gel sponge scaffolds. J. Biomed. Mater. Res. Part A 2009, 89A, 1118-1124.

212. Pereira Lopes, F.R.; Camargo de Moura Campos, L.; Dias Corrêa, J., Jr.; Balduino, A.; Lora, S.; Langone, F.; Borojevic, R.; Blanco Martinez, A.M. Bone marrow stromal cells and resorbable collagen guidance tubes enhance sciatic nerve regeneration in mice. Exp. Neurol. 2006, 198, 457-468.

213. Nie, X.; Zhang, Y.J.; Tian, W.D.; Jiang, M.; Dong, R.; Chen, J.W.; Jin, Y. Improvement of peripheral nerve regeneration by a tissue-engineered nerve filled with ectomesenchymal stem cells. Int. J. Oral Maxillofac. Surg. 2007, 36, 32-38.

214. Kingham, P.J.; Kalbermatten, D.F.; Mahay, D.; Armstrong, S.J.; Wiberg, M.; Terenghi, G. Adipose-derived stem cells differentiate into a Schwann cell phenotype and promote neurite outgrowth in vitro. Exp. Neurol. 2007, 207, 267-274.

215. Murakami, T.; Fujimoto, Y.; Yasunaga, Y.; Ishida, O.; Tanaka, N.; Ikuta, Y.; Ochi, M. Transplanted neuronal progenitor cells in a peripheral nerve gap promote nerve repair. Brain Res. 2003, 974, 17-24.

216. Heine, W.; Conant, K.; Griffin, J.W.; Hoke, A. Transplanted neural stem cells promote axonal regeneration through chronically denervated peripheral nerves. Exp. Neurol. 2004, 189, 231-240.

217. Teng, Y.D.; Lavik, E.B.; Qu, X.; Park, K.I.; Ourednik, J.; Zurakowski, D.; Langer, R.; Snyder, E.Y. Functional recovery following traumatic spinal cord injury mediated by a unique polymer scaffold seeded with neural stem cells. Proc. Natl. Acad. Sci. USA 2002, 99, 3024-3029. 
218. Olson, H.E.; Rooney, G.E.; Gross, L.; Nesbitt, J.J.; Galvin, K.E.; Knight, A.; Chen, B.; Yaszemski, M.J.; Windebank, A.J. Neural stem cell- and schwann cell-loaded biodegradable polymer scaffolds support axonal regeneration in the transected spinal cord. Tissue Eng. Part A 2009, 15, 1797-1805.

219. Lee, S.-H.; Chung, Y.-N.; Kim, Y.-H.; Kim, Y.-J.; Park, J.-P.; Kwon, D.-K.; Kwon, O.-S.; Heo, J.-H.; Kim, Y.-H.; Ryu, S.; Kang, H.-J.; Paek, S.H.; Wang, K.-C.; Kim, S.U.; Yoon, B.-W. Effects of human neural stem cell transplantation in canine spinal cord hemisection. Neurol. Res. 2009, 31, 996-1002.

220. Pritchard, C.D.; Slotkin, J.R.; Yu, D.; Dai, H.; Lawrence, M.S.; Bronson, R.T.; Reynolds, F.M.; Teng, Y.D.; Woodard, E.J.; Langer, R.S. Establishing a model spinal cord injury in the African green monkey for the preclinical evaluation of biodegradable polymer scaffolds seeded with human neural stem cells. J. Neurosci. Meth. 2010, 188, 258-269.

221. Zahir, T.; Nomura, H.; Guo, X.D.; Kim, H.; Tator, C.; Morshead, C.; Shoichet, M. Bioengineering neural stem/progenitor cell-coated tubes for spinal cord injury repair. Cell Transplant. 2008, 17, 245-254.

222. Bozkurt, G.; Mothe, A.J.; Zahir, T.; Kim, H.; Shoichet, M.S.; Tator, C.H. Chitosan channels containing spinal cord-derived stem/progenitor cells for repair of subacute spinal cord injury in the rat. Neurosurgery 2010, 67, 1733-1744.

223. Johnson, P.J.; Parker, S.R.; Sakiyama-Elbert, S.E. Fibrin-based tissue engineering scaffolds enhance neural fiber sprouting and delay the accumulation of reactive astrocytes at the lesion in a subacute model of spinal cord injury. J. Biomed. Mater. Res. Part A 2010, 92A, 152-163.

224. Johnson, P.J.; Tatara, A.; Shiu, A.; Sakiyama-Elbert, S.E. Controlled release of neurotrophin-3 and platelet-derived growth factor from fibrin scaffolds containing neural progenitor cells enhances survival and differentiation into neurons in a subacute model of SCI. Cell Transplant. 2010, 19, 89-101.

225. Itskovitz-Eldor, J.; Schuldiner, M.; Karsenti, D.; Eden, A.; Yanuka, O.; Amit, M.; Soreq, H.; Benvenisty, N. Differentiation of human embryonic stem cells into embryoid bodies comprising the three embryonic germ layers. Mol. Med. 2000, 6, 88-95.

226. Cui, L.; Jiang, J.; Wei, L.; Zhou, X.; Fraser, J.L.; Snider, B.J.; Yu, S.P. Transplantation of embryonic stem cells improves nerve repair and functional recovery after severe sciatic nerve axotomy in rats. Stem Cells 2008, 26, 1356-1365.

227. Marchesi, C.; Pluderi, M.; Colleoni, F.; Belicchi, M.; Meregalli, M.; Farini, A.; Parolini, D.; Draghi, L.; Fruguglietti, M.E.; Gavina, M.; Porretti, L.; Cattaneo, A.; Battistelli, M.; Prelle, A.; Moggio, M.; Borsa, S.; Bello, L.; Spagnoli, D.; Gaini, S.M.; Tanzi, M.C.; Bresolin, N.; Grimoldi, N.; Torrente, Y. Skin-derived stem cells transplanted into resorbable guides provide functional nerve regeneration after sciatic nerve resection. Glia 2007, 55, 425-438.

228. Beresford, J.N.; Bennett, J.H.; Devlin, C.; Leboy, P.S.; Owen, M.E. Evidence for an inverse relationship between the differentiation of adipocytic and osteogenic cells in rat marrow stromal cell cultures. J. Cell Sci. 1992, 102, 341-351.

229. Lennon, D.P.; Haynesworth, S.E.; Young, R.G.; Dennis, J.E.; Caplan, A.I. A chemically defined medium supports in vitro proliferation and maintains the osteochondral potential of rat marrow-derived mesenchymal stem cells. Exp. Cell Res. 1995, 219, 211-222. 
230. Wakitani, S.; Saito, T.; Caplan, A.I. Myogenic cells derived from rat bone marrow mesenchymal stem cells exposed to 5-azacytidine. Muscle Nerve 1995, 18, 1417-1426.

231. Hofstetter, C.P.; Schwarz, E.J.; Hess, D.; Widenfalk, J.; El Manira, A.; Prockop, D.J.; Olson, L. Marrow stromal cells form guiding strands in the injured spinal cord and promote recovery. Proc. Natl. Acad. Sci. USA 2002, 99, 2199-2204.

232. Ankeny, D.P.; McTigue, D.M.; Jakeman, L.B. Bone marrow transplants provide tissue protection and directional guidance for axons after contusive spinal cord injury in rats. Exp. Neurol. 2004, 190, 17-31.

233. Pal, R.; Gopinath, C.; Rao, N.M.; Banerjee, P.; Krishnamoorthy, V.; Venkataramana, N.K.; Totey, S. Functional recovery after transplantation of bone marrow-derived human mesenchymal stromal cells in a rat model of spinal cord injury. Cytotherapy 2010, 12, 792-806.

234. Himes, B.T.; Neuhuber, B.; Coleman, C.; Kushner, R.; Swanger, S.A.; Kopen, G.C.; Wagner, J.; Shumsky, J.S.; Fischer, I. Recovery of function following grafting of human bone marrow-derived stromal cells into the injured spinal cord. Neurorehabil. Neural Repair 2006, 20, 278-296.

235. McKenzie, I.A.; Biernaskie, J.; Toma, J.G.; Midha, R.; Miller, F.D. Skin-derived precursors generate myelinating schwann cells for the injured and dysmyelinated nervous system. J. Neurosci. 2006, 26, 6651-6660.

236. Biernaskie, J.; Sparling, J.S.; Liu, J.; Shannon, C.P.; Plemel, J.R.; Xie, Y.; Miller, F.D.; Tetzlaff, W. Skin-derived precursors generate myelinating Schwann cells that promote remyelination and functional recovery after contusion spinal cord injury. J. Neurosci. 2007, 27, 9545-9559.

237. di Summa, P.G.; Kingham, P.J.; Raffoul, W.; Wiberg, M.; Terenghi, G.; Kalbermatten, D.F. Adipose-derived stem cells enhance peripheral nerve regeneration. J. Plast Reconstr. Aesthet. Surg. 2010, 63, 1544-1552.

238. Li, B.C.; Jiao, S.S.; Xu, C.A.; You, H.; Chen, J.M. PLGA conduit seeded with olfactory ensheathing cells for bridging sciatic nerve defect of rats. J. Biomed. Mater. Res. Part A 2010 , 94A, 769-780.

239. Su, Z.; He, C. Olfactory ensheathing cells: Biology in neural development and regeneration. Prog. Neurobiol. 2010, 92, 517-532.

240. Pearse, D.D.; Sanchez, A.R.; Pereira, F.C.; Andrade, C.M.; Puzis, R.; Pressman, Y.; Golden, K.; Kitay, B.M.; Blits, B.; Wood, P.M.; Bartlett Bunge, M. Transplantation of Schwann cells and/or olfactory ensheathing glia into the contused spinal cord: Survival, migration, axon association, and functional recovery. Glia 2007, 55, 976-1000.

241. Ramon-Cueto, A.; Cordero, M.I.; Santos-Benito, F.F.; Avila, J. Functional recovery of paraplegic rats and motor axon regeneration in their spinal cords by olfactory ensheathing glia. Neuron 2000, 25, 425-435.

242. Woodhall, E.; West, A.K.; Chuah, M.I. Cultured olfactory ensheathing cells express nerve growth factor, brain-derived neurotrophic factor, glia cell line-derived neurotrophic factor and their receptors. Brain Res. Mol. Brain Res. 2001, 88, 203-213. 
243. Au, E.; Richter, M.W.; Vincent, A.J.; Tetzlaff, W.; Aebersold, R.; Sage, E.H.; Roskams, A.J. SPARC from olfactory ensheathing cells stimulates Schwann cells to promote neurite outgrowth and enhances spinal cord repair. J. Neurosci. 2007, 27, 7208-7221.

244. Li, B.C.; Li, Y.; Chen, L.F.; Chang, J.Y.; Duan, Z.X. Olfactory ensheathing cells can reduce the tissue loss but not the cavity formation in contused spinal cord of rats. J. Neurol. Sci. 2011, 303, 67-74.

245. Aoki, M.; Kishima, H.; Yoshimura, K.; Ishihara, M.; Ueno, M.; Hata, K.; Yamashita, T.; Iwatsuki, K.; Yoshimine, T. Limited functional recovery in rats with complete spinal cord injury after transplantation of whole-layer olfactory mucosa Laboratory investigation. J. Neurosurg.-Spine 2010, 12, 122-130.

246. Novikova, L.N.; Lobov, S.; Wiberg, M.; Novikov, L.N. Efficacy of olfactory ensheathing cells to support regeneration after spinal cord injury is influenced by method of culture preparation. Exp. Neurol. 2011, 229, 132-142.

247. Facchiano, F.; Fernandez, E.; Mancarella, S.; Maira, G.; Miscusi, M.; D’Arcangelo, D.; Cimino-Reale, G.; Falchetti, M.L.; Capogrossi, M.C.; Pallini, R. Promotion of regeneration of corticospinal tract axons in rats with recombinant vascular endothelial growth factor alone and combined with adenovirus coding for this factor. J. Neurosurg. 2002, 97, 161-168.

248. Duan, Y.-W.; Lu, G. Effect of vascular endothelial growth factor on cell apoptosis after spinal cord injury in rats. J. China Med. Univ. 2006, 35, 267-268.

249. De Laporte, L.; des Rieux, A.; Tuinstra, H.M.; Zelivyanskaya, M.L.; De Clerck, N.M.; Postnov, A.A.; Preat, V.; Shea, L.D. Vascular endothelial growth factor and fibroblast growth factor 2 delivery from spinal cord bridges to enhance angiogenesis following injury. J. Biomed. Mater. Res. Part A 2011, 98, 372-382.

250. Widenfalk, J.; Lipson, A.; Jubran, M.; Hofstetter, C.; Ebendal, T.; Cao, Y.; Olson, L. Vascular endothelial growth factor improves functional outcome and decreases secondary degeneration in experimental spinal cord contusion injury. Neuroscience 2003, 120, 951-960.

251. Benton, R.L.; Whittemore, S.R. VEGF(165) therapy exacerbates secondary damage following spinal cord injury. Neurochem. Res. 2003, 28, 1693-1703.

252. Narazaki, D.K.; Barros Filho, T.E.P.D.; Oliveira, C.R.G.C.M.D.; Cristante, A.F.; Iutaka, A.S.; Marcon, R.M.; Oliveira, R.P. Spinal cord regeneration: The action of neurotrophin-3 in spinal cord injury in rats. Clinics (Sao Paulo, Brazil) 2006, 61, 453-460.

253. Tuszynski, M.H.; Grill, R.; Jones, L.L.; Brant, A.; Blesch, A.; Low, K.; Lacroix, S.; Lu, P. NT-3 gene delivery elicits growth of chronically injured corticospinal axons and modestly improves functional deficits after chronic scar resection. Exp. Neurol. 2003, 181, 47-56.

254. Cuevas, P.; Carceller, F.; Gimenezgallego, C. Acidic fibroblast growth factor prevents death of spinal cord motoneurons in newborn rats after nerve section. Neurol. Res. 1995, 17, 396-399.

255. Cheng, H.; Cao, Y.H.; Olson, L. Spinal cord repair in adult paraplegic rats: Partial restoration of hind limb function. Science 1996, 273, 510-513.

256. Huang, W.-C.; Kuo, H.-S.; Tsai, M.-J.; Ma, H.; Chiu, C.-W.; Huang, M.-C.; Yang, L.-H.; Chang, P.-T.; Lin, Y.-L.; Kuo, W.-C.; Lee, M.-J.; Liu, J.-C.; Cheng, H. Adeno-associated virus-mediated human acidic fibroblast growth factor expression promotes functional recovery of spinal cord-contused rats. J. Gene Med. 2011, 13, 283-289. 
257. Tsai, M.-C.; Shen, L.-F.; Kuo, H.-S.; Cheng, H.; Chak, K.-F. Involvement of acidic fibroblast growth factor in spinal cord injury repair processes revealed by a proteomics approach. Mol. Cell. Proteomics 2008, 7, 1668-1687.

258. Martens, D.J.; Seaberg, R.M.; van der Kooy, D. In vivo infusions of exogenous growth factors into the fourth ventricle of the adult mouse brain increase the proliferation of neural progenitors around the fourth ventricle and the central canal of the spinal cord. Eur. J. Neurosci. 2002, 16, 1045-1057.

259. Shihabuddin, L.S.; Ray, J.; Gage, F.H. FGF-2 is sufficient to isolate progenitors found in the adult mammalian spinal cord. Exp. Neurol. 1997, 148, 577-586.

260. Meijs, M.F.L.; Timmers, L.; Pearse, D.D.; Tresco, P.A.; Bates, M.L.; Joosten, E.A.J.; Bunge, M.B.; Oudega, M. Basic fibroblast growth factor promotes neuronal survival but not Behavioral recovery in the transected and Schwann cell implanted rat thoracic spinal cord. J. Neurotrauma 2004, 21, 1415-1430.

261. Romero, M.I.; Rangappa, N.; Garry, M.G.; Smith, G.M. Functional regeneration of chronically injured sensory afferents into adult spinal cord after neurotrophin gene therapy. J. Neurosci. 2001, 21, 8408-8416.

262. Joosten, E.A.J.; Houweling, D.A. Local acute application of BDNF in the lesioned spinal cord anti-inflammatory and anti-oxidant effects. Neuroreport 2004, 15, 1163-1166.

263. Mitsui, T.; Fischer, I.; Shurnsky, J.S.; Murray, M. Transplants of fibroblasts expressing BDNF and NT-3 promote recovery of bladder and hindlimb function following spinal contusion injury in rats. Exp. Neurol. 2005, 194, 410-431.

264. Jain, A.; Kim, Y.T.; McKeon, R.J.; Bellamkonda, R.V. In situ gelling hydrogels for conformal repair of spinal cord defects, and local delivery of BDNF after spinal cord injury. Biomaterials 2006, 27, 497-504.

265. Sasaki, M.; Radtke, C.; Tan, A.M.; Zhao, P.; Hamada, H.; Houkin, K.; Honmou, O.; Kocsis, J.D. BDNF-hypersecreting human mesenchymal stem cells promote functional recovery, axonal sprouting, and protection of corticospinal neurons after spinal cord injury. J. Neurosci. 2009, 29, 14932-14941.

266. Liang, W.; Han, Q.; Jin, W.; Xiao, Z.; Huang, J.; Ni, H.; Chen, B.; Kong, J.; Wu, J.; Dai, J. The promotion of neurological recovery in the rat spinal cord crushed injury model by collagen-binding BDNF. Biomaterials 2010, 31, 8634-8641.

267. Bryan, D.J.; Holway, A.H.; Wang, K.K.; Silva, A.E.; Trantolo, D.J.; Wise, D.; Summerhayes, I.C. Influence of glial growth factor and Schwann cells in a bioresorbable guidance channel on peripheral nerve regeneration. Tissue Eng. 2000, 6, 129-138.

268. Aebischer, P.; Salessiotis, A.N.; Winn, S.R. Basic fibroblast growth factor released from synthetic guidance channels facilitates peripheral nerve regeneration across long nerve gaps. J. Neurosci. Res. 1989, 23, 282-289.

269. Krikorian, D.; Manthorpe, M.; Varon, S. Purified mouse Schwann cells: Mitogenic effects of fetal calf serum and fibroblast growth factor. Develop. Neurosci. 1982, 5, 77-91.

270. Cordeiro, P.G.; Seckel, B.R.; Lipton, S.A.; Damore, P.A.; Wagner, J.; Madison, R. Acidic fibroblast growth factor enhances peripheral nerve regeneration in vivo. Plast. Reconstr. Surg. 1989, 83, 1013-1019. 
271. Hontanilla, B.; Auba, C.; Gorria, O. Nerve regeneration through nerve autografts after local administration of brain-derived neurotrophic factor with osmotic pumps. Neurosurgery 2007, 61, 1268-1274.

272. Kanaya, F.; Firrell, J.C.; Breidenbach, W.C. Sciatic function index, nerve conduction tests, muscle contraction, and axon morphometry as indicators of regeneration. Plast. Reconstr. Surg. 1996, 98, 1264-1271.

273. Ogata, T.; Yamamoto, S.; Nakamura, K.; Tanaka, S. Signaling axis in Schwann cell proliferation and differentiation. Mol. Neurobiol. 2006, 33, 51-61.

274. Koh, H.S.; Yong, T.; Chan, C.K.; Ramakrishna, S. Enhancement of neurite outgrowth using nano-structured scaffolds coupled with laminin. Biomaterials 2008, 29, 3574-3582.

275. Ahmed, I.; Liu, H.Y.; Mamiya, P.C.; Ponery, A.S.; Babu, A.N.; Weik, T.; Schindler, M.; Meiners, S. Three-dimensional nanofibrillar surfaces covalently modified with tenascin-C-derived peptides enhance neuronal growth in vitro. J. Biomed. Mater. Res. Part A 2006, 76A, 851-860.

276. Miller, C.; Jeftinija, S.; Mallapragada, S. Micropatterned Schwann cell-seeded biodegradable polymer substrates significantly enhance neurite alignment and outgrowth. Tissue Eng. 2001, 7, 705-715.

277. Hurtado, A.; Cregg, J.M.; Wang, H.B.; Wendell, D.F.; Oudega, M.; Gilbert, R.J.; McDonald, J.W. Robust CNS regeneration after complete spinal cord transection using aligned poly-L-lactic acid microfibers. Biomaterials 2011, 32, 6068-6079.

278. Chow, W.N.; Simpson, D.G.; Bigbee, J.W.; Colello, R.J. Evaluating neuronal and glial growth on electrospun polarized matrices: Bridging the gap in percussive spinal cord injuries. Neuron Glia Biol. 2007, 3, 119-126.

279. Kim, Y.T.; Haftel, V.K.; Kumar, S.; Bellamkonda, R.V. The role of aligned polymer fiber-based constructs in the bridging of long peripheral nerve gaps. Biomaterials 2008, 29, 3117-3127.

280. Schnell, E.; Klinkhammer, K.; Balzer, S.; Brook, G.; Klee, D.; Dalton, P.; Mey, J. Guidance of glial cell migration and axonal growth on electrospun nanofibers of poly-e-caprolactone and a collagen/poly-E-caprolactone blend. Biomaterials 2007, 28, 3012-3025.

281. Shen, Y.; Qian, Y.; Zhang, H.; Zuo, B.; Lu, Z.; Fan, Z.; Zhang, P.; Zhang, F.; Zhou, C. Guidance of olfactory ensheathing cell growth and migration on electrospun silk fibroin scaffolds. Cell Transplant. 2010, 19, 147-157.

282. Yang, F.; Xu, C.Y.; Kotaki, M.; Wang, S.; Ramakrishna, S. Characterization of neural stem cells on electrospun poly(L-lactic acid) nanofibrous scaffold. J. Biomater. Sci.-Polym. Ed. 2004, 15, 1483-1497.

283. Yang, F.; Murugan, R.; Wang, S.; Ramakrishna, S. Electrospinning of nano/micro scale poly(L-lactic acid) aligned fibers and their potential in neural tissue engineering. Biomaterials 2005, 26, 2603-2610.

284. Zhu, Y.Q.; Wang, A.J.; Shen, W.Q.; Patel, S.; Zhang, R.; Young, W.L.; Li, S. Nanofibrous patches for spinal cord regeneration. Adv. Funct. Mater. 2010, 20, 1433-1440.

285. Chew, S.Y.; Mi, R.; Hoke, A.; Leong, K.W. The effect of the alignment of electrospun fibrous scaffolds on Schwann cell maturation. Biomaterials 2008, 29, 653-661. 
286. Xie, J.; MacEwan, M.R.; Willerth, S.M.; Li, X.; Moran, D.W.; Sakiyama-Elbert, S.E.; Xia, Y. Conductive core-sheath nanofibers and their potential application in neural tissue engineering. Adv. Funct. Mater. 2009, 19, 2312-2318.

287. Townsend-Nicholson, A.; Jayasinghe, S.N. Cell electrospinning: A unique biotechnique for encapsulating living organisms for generating active biological microthreads/scaffolds. Biomacromolecules 2006, 7, 3364-3369.

288. Jayasinghe, S.N.; Townsend-Nicholson, A. Stable electric-field driven cone-jetting of concentrated biosuspensions. Lab Chip 2006, 6, 1086-1090.

289. Thompson, D.M.; Buettner, H.M. Oriented Schwann cell monolayers for directed neurite outgrowth. Ann. Biomed. Eng. 2004, 32, 1121-1131.

290. Wang, W.; Itoh, S.; Konno, K.; Kikkawa, T.; Ichinose, S.; Sakai, K.; Ohkuma, T.; Watabe, K. Effects of Schwann cell alignment along the oriented electrospun chitosan nanofibers on nerve regeneration. J. Biomed. Mater. Res. Part A 2009, 91A, 994-1005.

(C) 2011 by the authors; licensee MDPI, Basel, Switzerland. This article is an open access article distributed under the terms and conditions of the Creative Commons Attribution license (http://creativecommons.org/licenses/by/3.0/). 